\title{
Review on Heat Transfer Enhancement by Insert Devices
}

\author{
Md. Shamim Ahmed and Mohammad Zoynal Abedin
}

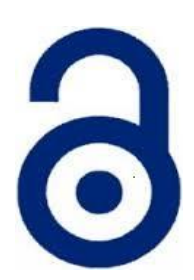

Received: 24 July 2020

Accepted: 05 October 2020

Published: 20 October 2020

Publisher: Deer Hill Publications

(c) 2020 The Author(s)

Creative Commons: CC BY 4.0

\begin{abstract}
The scientists revise the heat transfer enhancement techniques time to time to achieve better performance and to obtain optimized designs of heat exchangers. The present study reviews the performance and techniques of heat transfer enhancement using various insert devices such as twisted tape and wire coil insert as well as completely different forms of other inserts like air-foil shape inserts, $X$-shaped twisted tape inserts, baffles and V-winglets inserts with various types of medium and nanofluids. According to the summary of recent significant researches on the heat transfer enhancement by using different types of inserts and combinations of these inserts with various nanofluids showed that insert can indicatively enhance the heat transfer rate by modifying its geometry or configurations like twist ratio, length ratio, pitch ratio, segmented tape, perforated tape, angle of arrangements and insert quantities and so on which caused a considerable impact on performance characteristics of heat transfer enhancement along with the pressure drop and friction factor. It is revealed through reviewing the related literature that the highest value of equivalence heat transfer enhancement is as maximum as $400 \%, 300 \%$ and $9 \%$ for the twisted tape insert with helical tube, the air foil shaped inserts and for the wire coil inserts, respectively when compared with the smooth tube. In the case of baffles in nanofluids, as maximum as $255 \%$ equivalence heat transfer enhancement could be achieved when compared with that of baffles without nanofluids.
\end{abstract}

Keywords: Heat transfer enhancement, Performance Characteristics, Twisted tape inserts, Wire coil inserts, Inserts with Nanofluids.

NOMENCLATURE:

\begin{tabular}{ll}
\hline Abbreviation/Symbol & Meaning \\
\hline TT & Twisted Tape \\
HTC & Heat Transfer Coefficients \\
G & Mass flux \\
Q & Heat Flux \\
PTTT & Perforated Triple Twisted Tape Insert \\
TEE & Thermal enhancement efficiency \\
Pr & Prandtl number \\
Re & Reynolds number \\
FLTT & Full length twisted tape \\
HLUTT & Half-length upstream twisted tape \\
HLDTT & Half-length-downstream twisted tape \\
T-W & Delta-Wing Tape Inserts \\
PNW & Wing Pitch Ratio \\
R B & Relative Winglet Height \\
RP & Relative Winglet Pitch \\
DW & Discrete-V winglet tape \\
HTE & Heat Transfer Enhancement \\
HTP & Heat Transfer Performance \\
HTR & Heat Transfer Rate \\
EF & Efficiency Factor \\
\hline
\end{tabular}

Md. Shamim Ahmed and Mohammad Zoynal Abedin $₫$

Department of Mechanical Engineering

Dhaka University of Engineering and Technology

Gazipur 1700, Bangladesh

E-mail: abedin.mzoynal@duet.ac.bd

Reference: Ahmed, M. S. and Abedin, M. Z. (2020). Review on Heat Transfer Enhancement by Insert Devices. International Journal of Engineering Materials and Manufacture, 5(4), 130-147. 


\section{INTRODUCTION}

The researchers investigate different ways of heat transfer enhancement techniques for reducing the cost and size of heat exchanger for many years. Three main categories (Active, Passive and Compound methods) are considered as enhancement techniques to increase heat transfer efficiency. The active method utilizes external power to achieve the desired goal and rarely use in practical applications whereas the passive method does not require external power to achieve the fluid motion and heat transfer enhancement. On the contrary, the compound method is the combination of two or more methods that have limited applications due to its complex design despite it is considered as a significant enhancer. For convenient usage, passive techniques are important topics for scientists and researchers during recent decades. Innumerable experimental studies have been conducted to improve the heat transfer rates by these techniques. Scientists preferred passive heat transfer enhancement techniques due to their simplicity and applicability in many applications [1]. In recent years, heat transfer technology has been widely applied to refrigeration and air conditioning, automobile, process industries, etc. The main purpose of heat transfer enhancement techniques is to reduce the thermal resistance either by achieving the effective heat transfer surface area or by creating turbulence in the fluid flowing inside the tube. There are various arrangements are used and experimented to get better heat transfer rate such as insertion in tubes, the tube with fins, different tube shapes, corrugated tubes, baffle arrangements as well as different mediums like water, air, and nanofluids. The rearrangements of these different components are used for obtaining various purposes like increases the surface contact area of the fluid, create a swirl in the flow, and decrease the pressure drop to get enhancement heat transfer rates [2].

Overall, rough surfaces or extended surfaces are used to increasing the effective surface area whereas inserts, winglets, turbulators, etc. are used for generating the turbulence [3]. Based on scientific experiences, various types of inserts such as modified twisted tapes, wire coil, baffles, wire mesh, longitudinal swirl generators, and other types of tube inserts have been designed and studied numerically or experimentally. Some researchers summarized the functions of different types of the insert which mainly enhanced single-phase convective heat transfer in heat exchangers by mixing main flow and the turbulence in the boundary layer region [4].

In recent years, heat transfer technology has been widely applied to devise applications in refrigeration, automotive, method industries as heat exchanger system. Heat exchanger systems are used in different processes like conversion, utilization and recovery of thermal energy in various industrial, domestic applications and commercial processes. The most common examples include steam generation and condensation in power cogeneration plants widely used the heat exchanger to get better performance. The heating and cooling in thermal processing of pharmaceutical products manufacturing, chemicals industries and waste heat recovery plants are also utilizing the heat enhancement process by various enhancer to increase the heat exchanger efficiency. The increase in heat transfer performance can lead to a more economical design of heat exchanger which can help to make savings of energy, materials and cost which is related to a heat exchange process. This design also obeys many techniques termed as heat transfer augmentation which has an indicative impact on the enhancement of thermal performance. The present study investigated the heat transfer enhancement in various arrangements with insert devices as an important passive technique and their impacts on different mediums and configurations.

\section{INSERT DEVICES}

As part of heat transfer enhancement, inserts are widely used in pipe flow because it can break the boundary layer and increase the heat transfer rates. Inserts require additional arrangements to create turbulence of fluids or mediums which can enhance the heat transfer. There are several types of inserts using for heat transfer enhancement. For instance, twisted tape, wire coils, ribs, baffles, plates, helical screw insert, mesh inserts, convergent or divergent conical rings, conical rings, etc. which are major types of the insert. Tube insert devices including twisted tape, wire coils, extended surfaces, and wire mesh inserts are considered as the most important techniques of passive heat transfer enhancement methods. Among them, twisted tape and wire coil inserts are widely applied to others. This paper tried to reveal only the very recent significant study on twisted tape (TT) and wire coils inserts [5].

\section{TWISTED TAPE INSERTS}

Twisted tapes are the metallic twisted strips using some of the suitable techniques as per the required shape and dimension, which are inserted in the flow to enhance the heat transfer [6]. To enhance the thermal efficiency of heat exchangers, scientists found that different types of developed twisted tape inserts are suitable as passive augmentation techniques and strengthen the heat transfer efficiency for heat exchangers [7]. Among the swirl flow devices, twisted tape inserts are very popular because of their better thermal performance in flow mediums like single-phase flow, two-phase flow, boiling, condensation, etc. Generally, twisted tape inserts increase the heat transfer enhancement with an increase in the pressure drop [8]. This enhancement of heat transfer techniques for a twisted tape is achieved by a mixing of the boundary layer rather than an increase in heat transfer surface area. Figure 1 shows a typical configuration of plain TT which is commonly used [9].

The very recent study of Feng et al., [10] proved that the convective heat transfer in a swirl flow is similar to that in a straight flow. The investigation also found that the tubes with TT inserts show an enhanced heat transfer coefficient compared to the wall temperature of plain tubes and TT tubes by experiment the effects of thermal performance characteristics like the system pressure, heat flux, buoyancy, thermal acceleration and twist ratio with a 
wide range of supercritical conditions for a kerosene-type hydrocarbon fuel with a twisted tape insert [10]. Figure 2(a) shows the heat flux and the average HTC variation for the plain and TT tubes at a pressure of 3.0 MPa. and it shows that the average HTC for the TT tubes is larger than that for the plain tubes. In another Figure 2 (b) shows the overall heat transfer performance for the TT tube with different twist ratios is larger than the plain tube.

The effects of porosity of perforated triple twisted tapes (PTTT) on heat transfer enhancement and friction factor as an important thermal performance characteristic of a heat exchanger has been studied and found that the highest heat transfer of $320 \%$, the highest friction factor of 355\% and maximum thermal enhancement efficiency (TEE) of 1.5 is obtained at a porosity of $4.6 \%$ with PTTT insert compared to the smooth tube. Because with decreasing the porosity of the tape inserts the Nusselt number, friction factor, and TEE are increased. The predicted vs. experimental relationships of heat transfer, friction factor and TEE are shown in Figure 3(a), Figure 3(b), and Figure 3(c). It has been observed that the predicted data are well adjusted with those obtained the data for the experiment of heat transfer, friction factor and TEE within data range of ( +6 to -5$) \%,(+4$ to -6$) \%$, and (+6 to -3$) \%$, respectively [11].

Another recent study of Gugulothu [12] has been conducted a CFD analysis to investigate the ribbed tube with different twisted tapes insert (FLTT, HLUTT, HLDTT) at uniform heat flux condition to sort out the performance characteristics of thermal efficiency, friction factor and mean Nusselt number. Air was treated as a working fluid and the simulations (Ansys Fluent) were carried out in a turbulent region by choosing suitable Re and found FTTT showed a better heat transfer, friction factor and enhancement efficiency compared to HLTT as a numerical result. The main purpose of this comparison was to understand the rate of heat flow and temperature distribution along with the various length of the pipes. The study also observed that in the case of HLUTT and HLDTT tapes, there is a decrease in the thermal performance factor with an increase in Re and twisted ratios which are showing in Figure 4, whereas in the case of FLTT, the thermal performance factor tends to increase with different twisted ratios and improvements of $\operatorname{Re}[12]$.

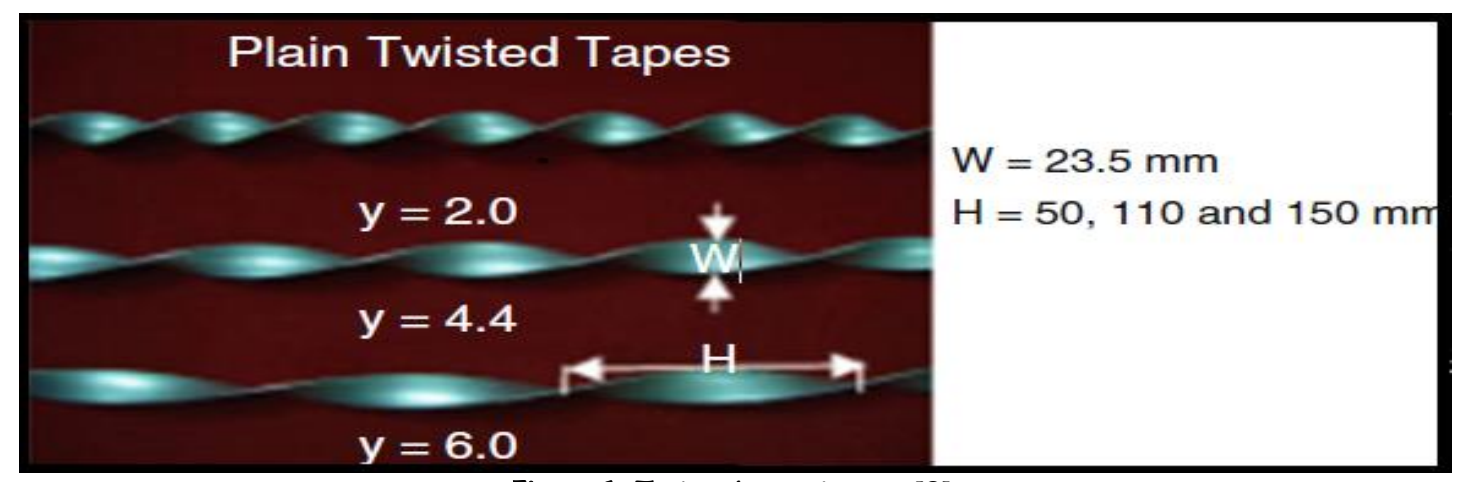

Figure 1: Twisted tape inserts [9].
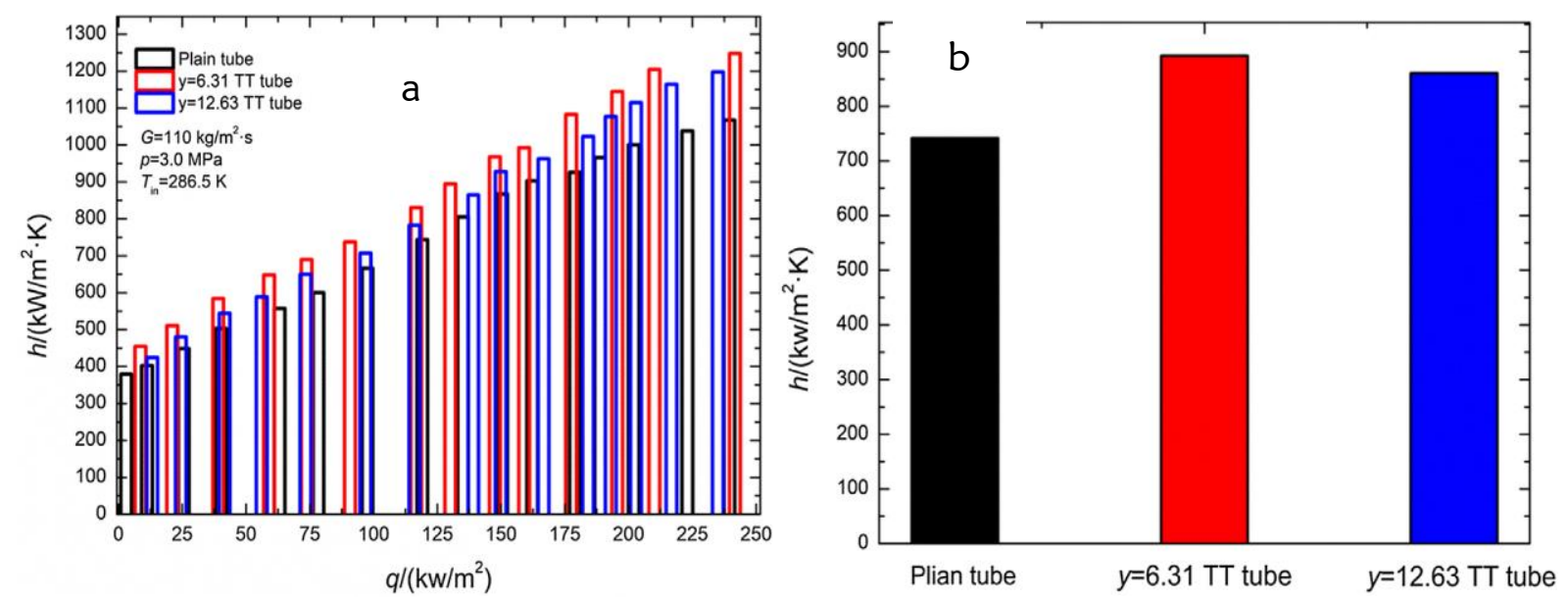

Figure 2: (a) Heat flux and average HTC variation in the plain and TT tubes. (b) The overall heat transfer performance for TT tubes and the plain tubes [10]. 

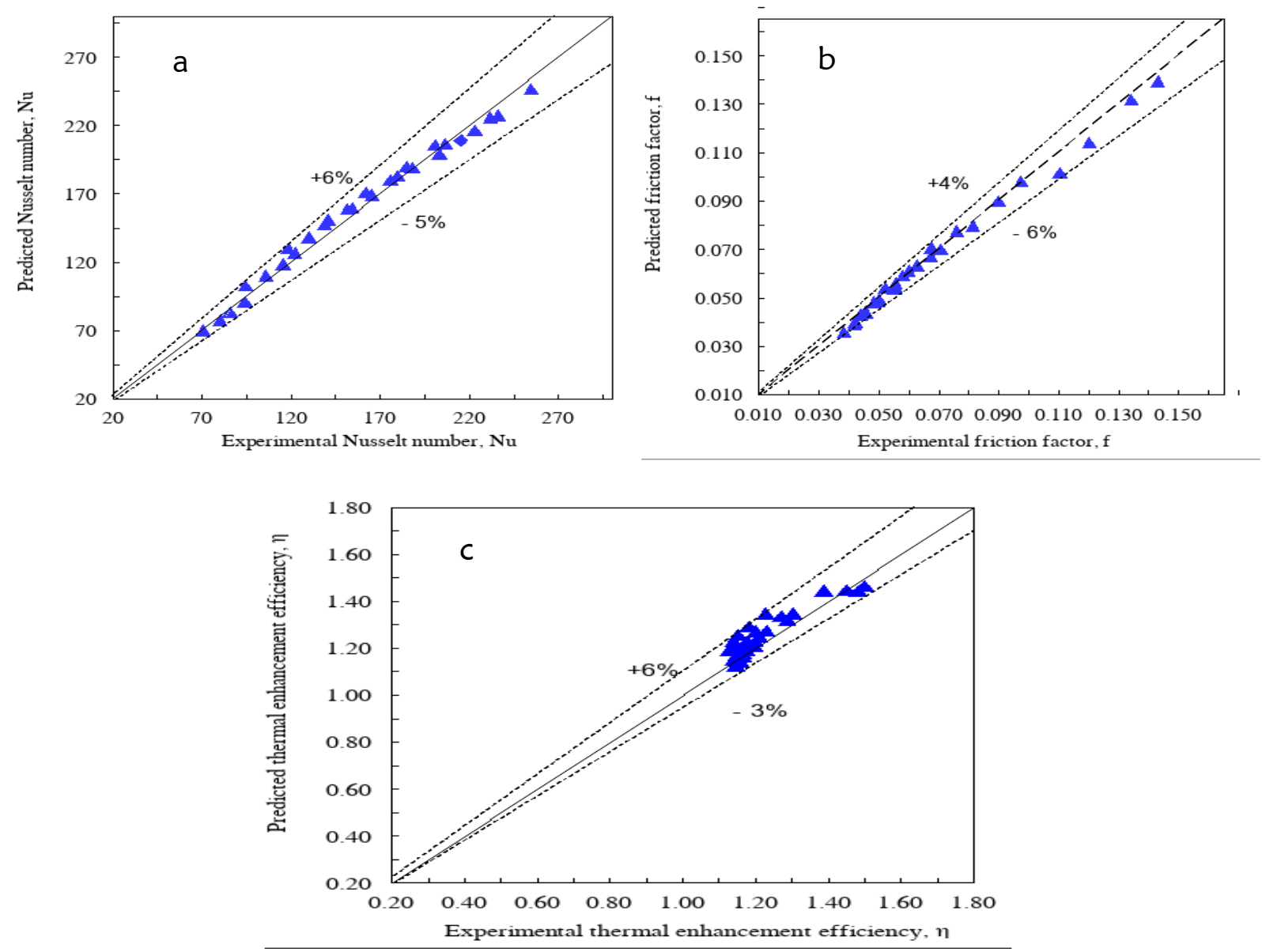

Figure 3: Comparison between the predicted and experimental data (a) Nusselt number (b) Friction factor (c) Thermal enhancement efficiency [11].

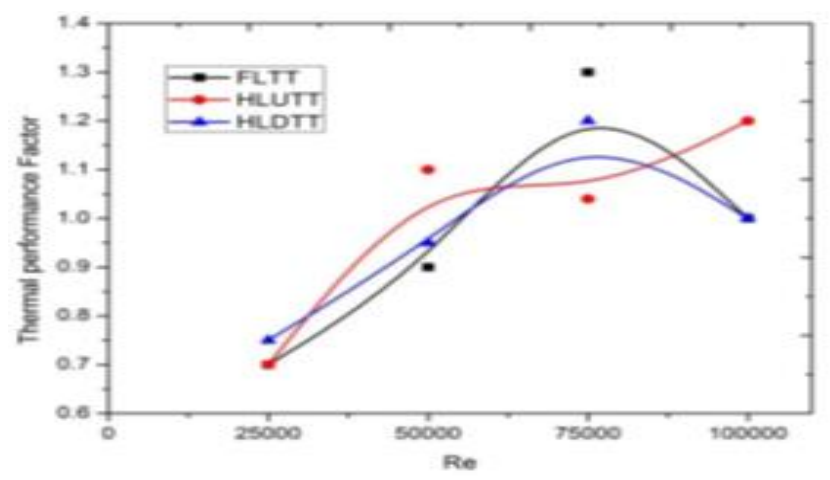

Figure 4: Variation of Re with thermal performance factor for a twist ratio of 0.14 with $Q=2300 \mathrm{~W} / \mathrm{m}^{2}[12]$.

Paneliya et al., [13] found 1.27 times larger heat transfer enhancement for X-Shaped tapes than twisted tape inserts by comparing the thermal characteristic of water flowing in a tube equipped with X-tape and twisted tape to investigate the effect of insert tape geometry on the heat exchanger tubes [13]. The material of the insert tapes was stainless steel in this study. The thermal performance of the heat exchanger tube has been analyzed for this experiment in terms of heat transfer rate $(\mathrm{Q})$, Nusselt Number $(\mathrm{Nu})$ and friction factor (f). The investigation also conducts a CFD analysis to validate the obtained results and observed that the modified geometry of tapes played a vital role to enhance the heat transfer characteristic and thermal performance where turbulence intensity occurred, showed in Figure 5. 
The comparison between typical TT and sparsely placed TT with multiple transverse TT studied by Samruaisin et al., [14] and observed the tube with sparsely placed TT installed with multiple transverse twisted-baffles gave the highest thermal enhancement factor of 1.32. The study also found an additional flow disturbance caused by the multipletransverse twisted baffles and the combined actions of swirl flow caused by the twisted tape inserts [14]. Figure 6 shows the copper tube with a sparsely placed twisted tape combined with multiple transverse twisted baffles.

Wijayantaa et al., [15] illustrated the limited number of studies of heat transfer enhancement regarding the wingpitch ratio. To experiment in this field, they improved single-phase convective heat transfer with water as working fluid under a condition of 5,300 to 14,500 Reynolds number. It is revealed from the study that the delta wing tape inserts with a wing-pitch ratio of 1.18 produces the greatest thermal performance factor of 1.15 and offers the highest average Nusselt number of $177 \%$ compared to a plain tube [15]. Figure 7(a) shows the geometry and Figure 7(b) illustrates the photograph of the delta wing tape inserts.

In the other recent investigation of Liu et al., [16] indicates that the geometric parameters like twist ratio and length ratio play an important role in heat transfer enhancement. The results showed that a segmented tape insert in pipe flow can increase the overall heat transfer rate by $23.5 \%$ and the friction factor by $235 \%$, while local improvement along the tube can be 2.8 times more than the plain tube [16]. Figure 8 illustrates the relationships between heat transfer coefficient and twist ratio along the tube.

a)

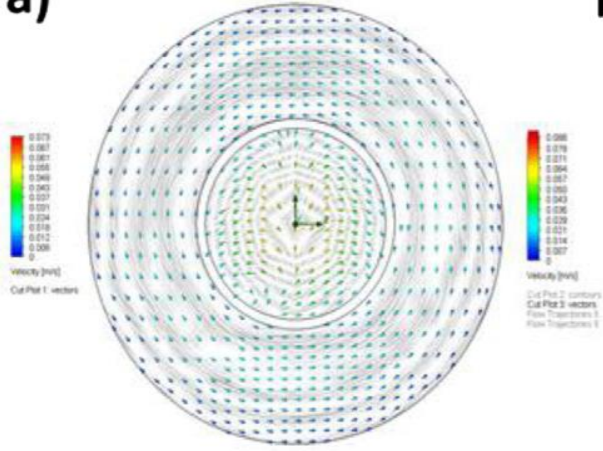

b)

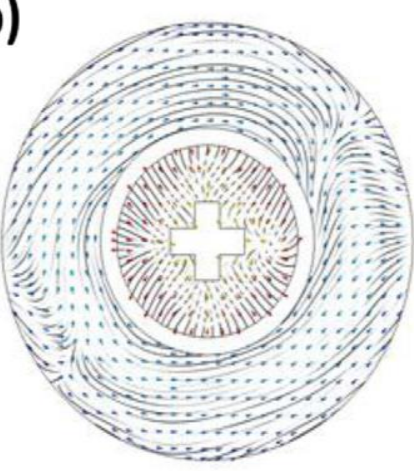

c)

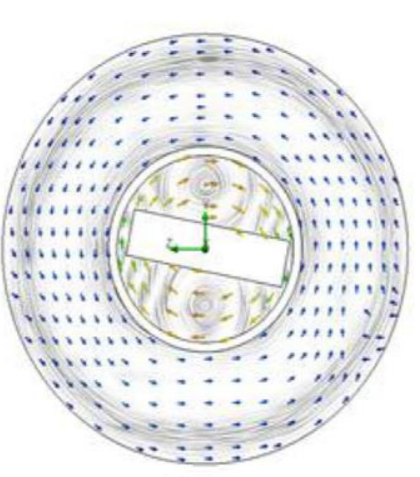

Figure 5: The turbulence intensity inside the different setups (a) plain tube (b) X-shape tape (c) stainless steel variable [13].

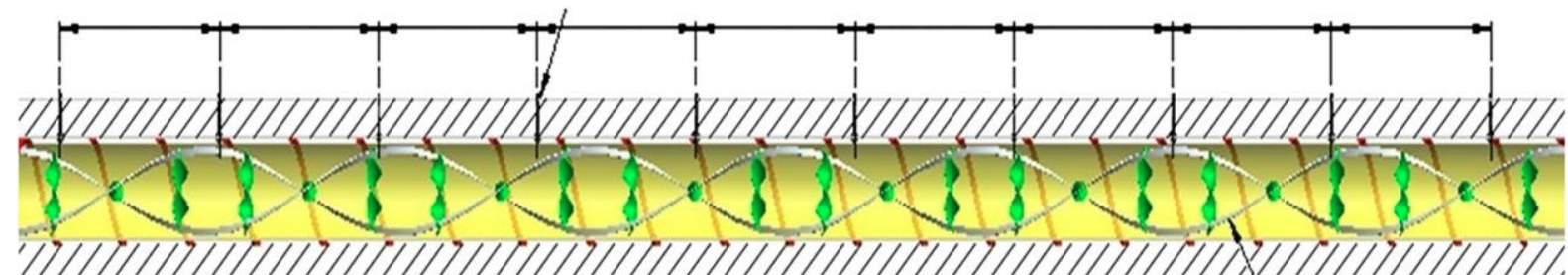

Figure 6: Copper tube with a sparsely placed twisted tape combined with multiple transverse twisted baffles [14]

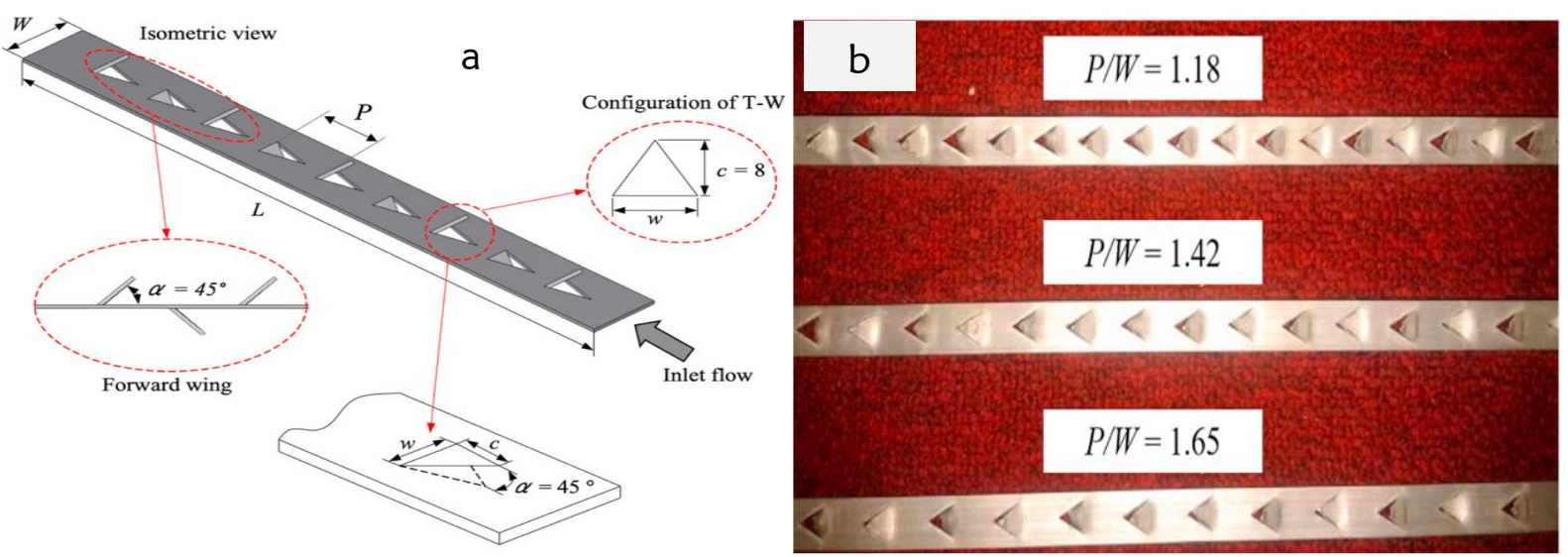

Figure 7: (a) Geometry of the delta wing tape inserts (b) photographs of delta-wing tape inserts [15]. 
To demonstrate the flow behaviors and corresponding heat transfer, Jundika et al., [17] added a twisted tape inserts in helical tube heat exchanger at a higher frictional pressure drop conditions and found four times enhanced heat transfer performance compared to conventional straight tube heat exchangers. The working methods of this experiment like lowering the twisting ratio and Prandtl number (air) respectively promote higher secondary flow and increase the Re number which increased the heat transfer enhancement ratio. Finally, it predicts the heat transfer and pressure drop for practical applications by developed a correlation between Nusselt number and friction factor for water and air as a fluid medium which is illustrated in Figure 9 and Figure 10, respectively [17].

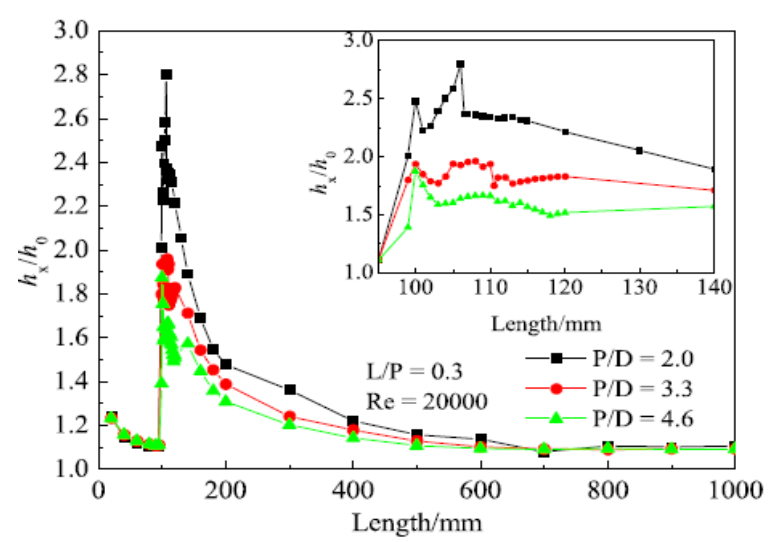

(a)

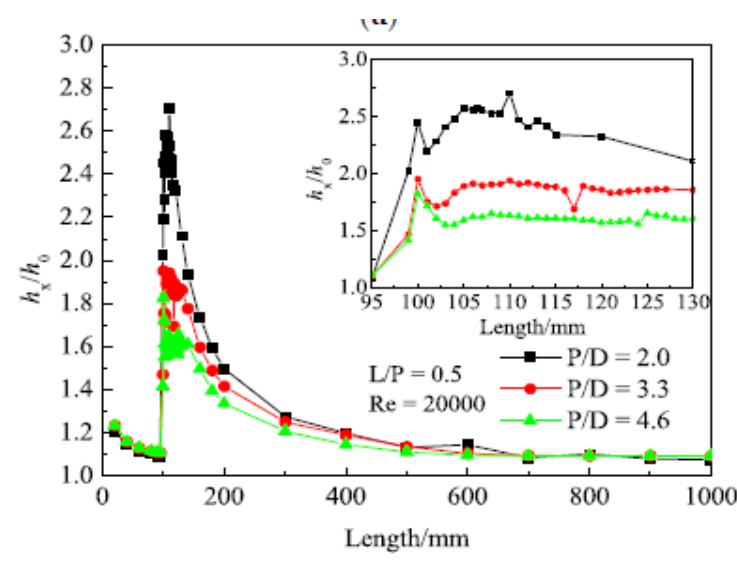

(b)

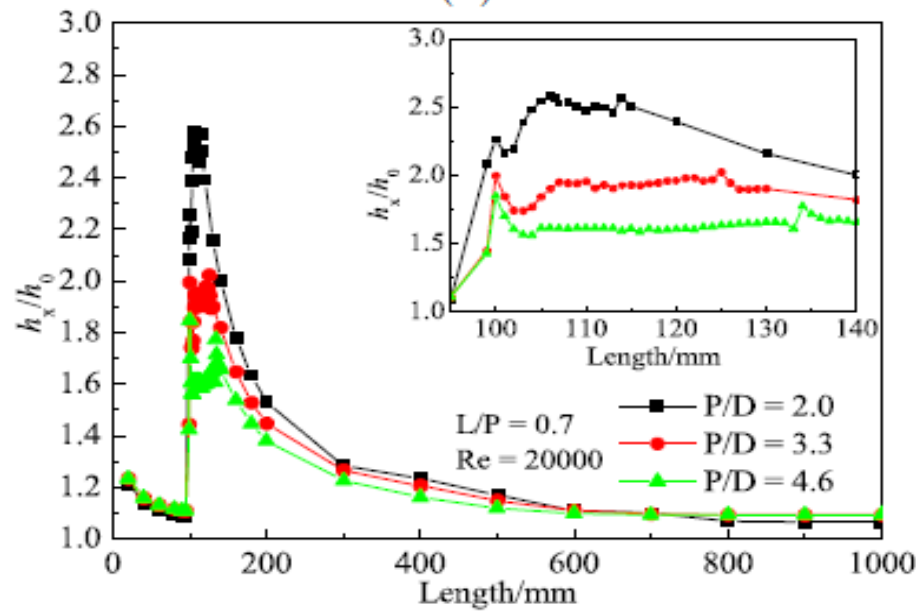

(c)

Figure 8: Relationship between heat transfer coefficient and twist ratio (P/D) along the tube: (a) Length ratio, L/P = 0.3 , (b) Length ratio, $L / P=0.5$, (c) Length ratio, $L / P=0.7$ [16].
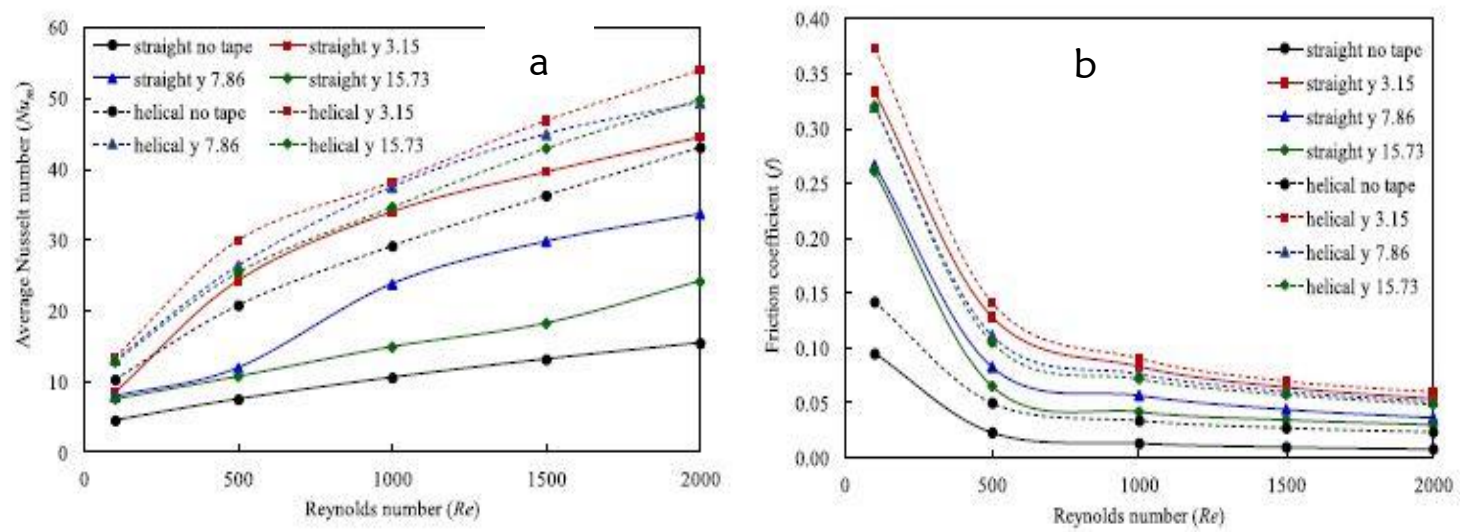

Figure 9: (a) Average Nusselt number of water flow for various configurations at $\mathrm{T}_{\text {wall }}=333.15 \mathrm{~K}$. (b) Friction coefficient of water flow for various configurations at $\mathrm{T}_{\text {wall }}=333.15 \mathrm{~K}$ [17]. 

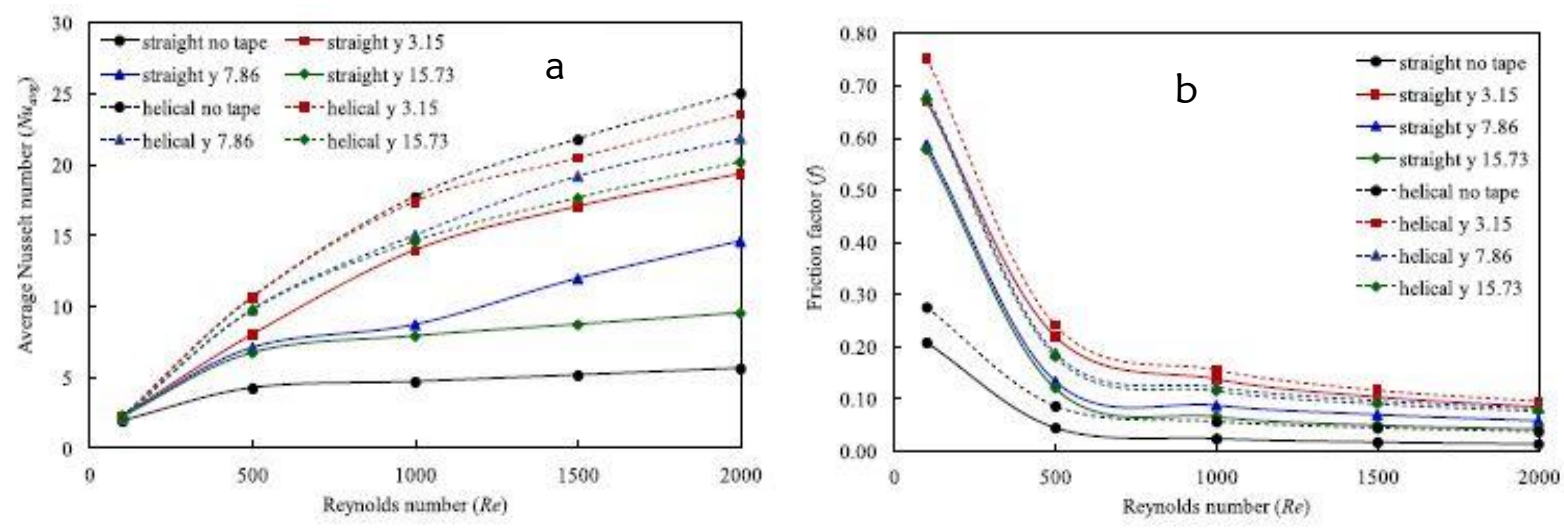

Figure 10: (a) Average Nusselt number of air flow for various configurations at $T_{\text {wall }}=333.15 \mathrm{~K}$. (b) Friction coefficient of air flow for various configurations at $\mathrm{T}_{\text {wall }}=333.15 \mathrm{~K}[17]$.

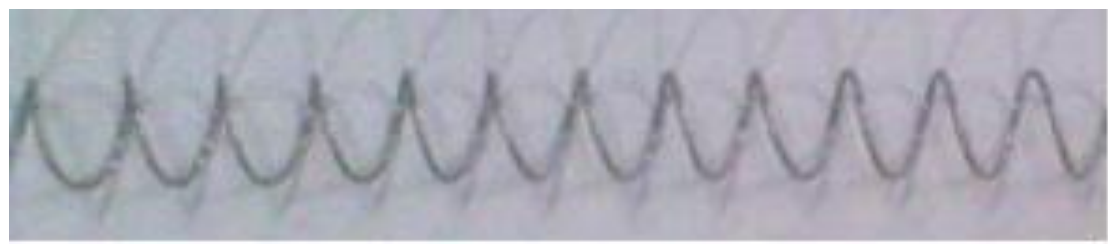

Figure 11: Wire coil insert [18].

\section{WIRE COIL INSERTS}

Wire-coil inserts have been utilized as another significant passive heat transfer enhancement technique besides the twisted tape inserts and widely used in various heat transfer equipment. This kind of inserts has several advantages compared to other enhancement techniques like easy installation and removal, simple manufacturing process with low cost, preservation of original plain tube from mechanical strength, the possibility of installation in an existing smooth tube heat exchanger, fouling mitigation in refineries, chemical industries, and marine applications. Figure 11 illustrates a wire coil insert that should be applied instead of a smooth one to obtain higher heat transfers [18].

Abedin and Sarkar [19] investigated the enhancement of turbulent heat transfer flow of air through one smooth tube and four different tubes with wire coil inserts at low Reynolds numbers and find that the turbulent heat transfer coefficient approximately two-folds higher, the friction factors could be as much as four-folds higher and the effectiveness might be as much as 1.25 folds higher than those for the smooth tubes with similar flow conditions showed in Figure 12(a). The investigation has also developed a correlation to predict the turbulent heat transfer coefficients through the tubes at low Reynolds numbers illustrate in Figure 12(b) [19].

Goudarzi and Jamali [20] used two-wire coil inserts with different geometry and aluminium oxide $\left(\mathrm{Al}_{2} \mathrm{O}_{3}\right)$ in ethylene glycol (EG) as nanofluid to experiment the heat transfer enhancement and found that the use of coils inserts enhanced heat transfer rates up to $9 \%$. The experiment concludes that the coil inserts with the nanofluid with a concentration of $0.08 \%, 0.5 \%$ and $1 \%$ result the thermal performance enhancement up to $5 \%$ as compared to the use of coil inserts alone [20]. Figure 13 demonstrates a relation between thermal performance factor and Reynolds number for tube inserts, where the values of thermal performance factors are not significantly different for different Reynolds numbers.

Wanga et al., [21] configured a helical coil device as $360^{\circ}$ plastic tubing with or without wire coil inserts placed after each $180^{\circ}$ of the main helical coil loops to investigate the flow and heat transfer characteristics of water. The setup influences the fluid mixing, pressure drop, and other thermal performance characteristics which should have a direct impact on the thermal performance of the helical coil heat transfer devices. The experimental results showed that the structural modifications with the wire coil of the conventional helical coil configuration led to enhance heat transfer in the test section while the pressure drop penalty increased slightly [21]. Table 1 depicts the pressure drop increases with the curvature ratio and lower pitch values of the wire coil in reversed loop helical coil tubes.

\section{OTHER TYPES OF INSERT DEVICES}

Besides twisted tape and wire-coil inserts, different types of inserts have been utilized in different industries and applications to get efficient heat transfer enhancements. Helical coils, air-foil shaped inserts, V-winglets such kind of enhancers which are applied on various applications to achieve better performance. 

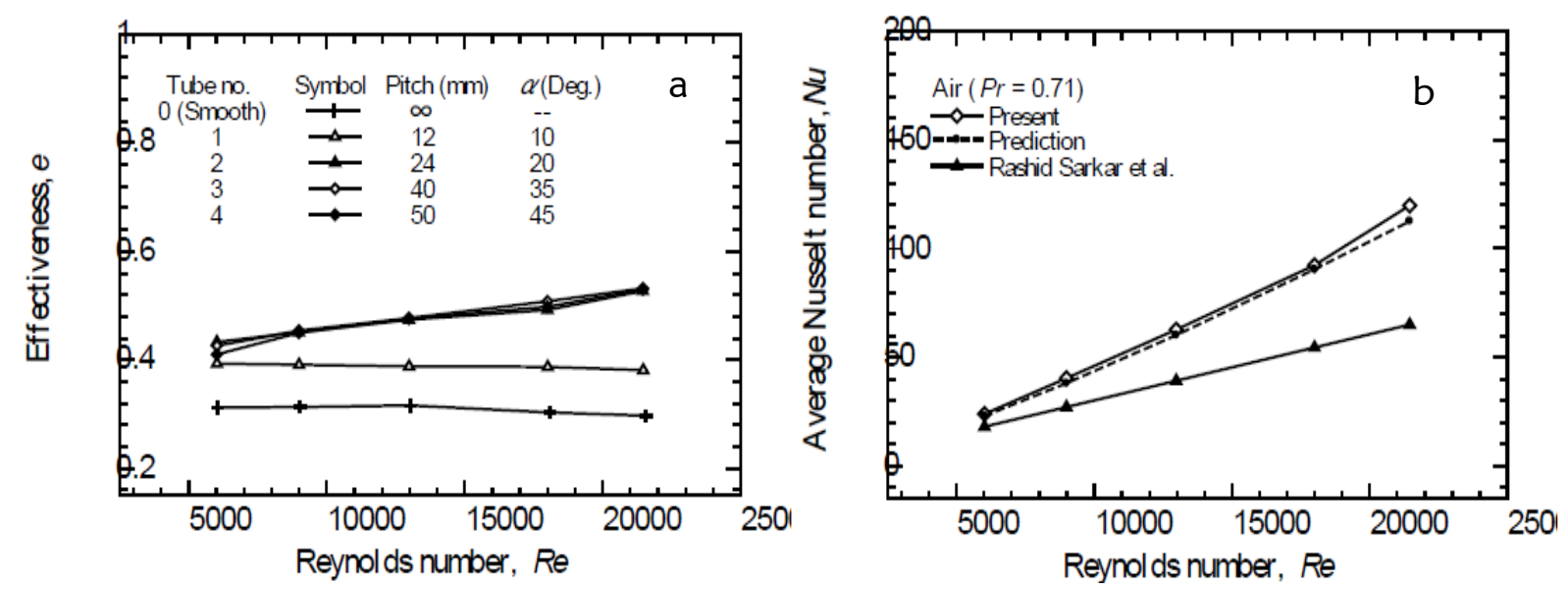

Figure 12: (a) Variation of average effectiveness against Reynolds number for smooth tube and wire-coil inserted tubes. (b) Prediction of heat transfer coefficients for wire-coil inserted tube (Pitch $=50 \mathrm{~mm}$, helix angle, $\alpha=450$ ) [19].

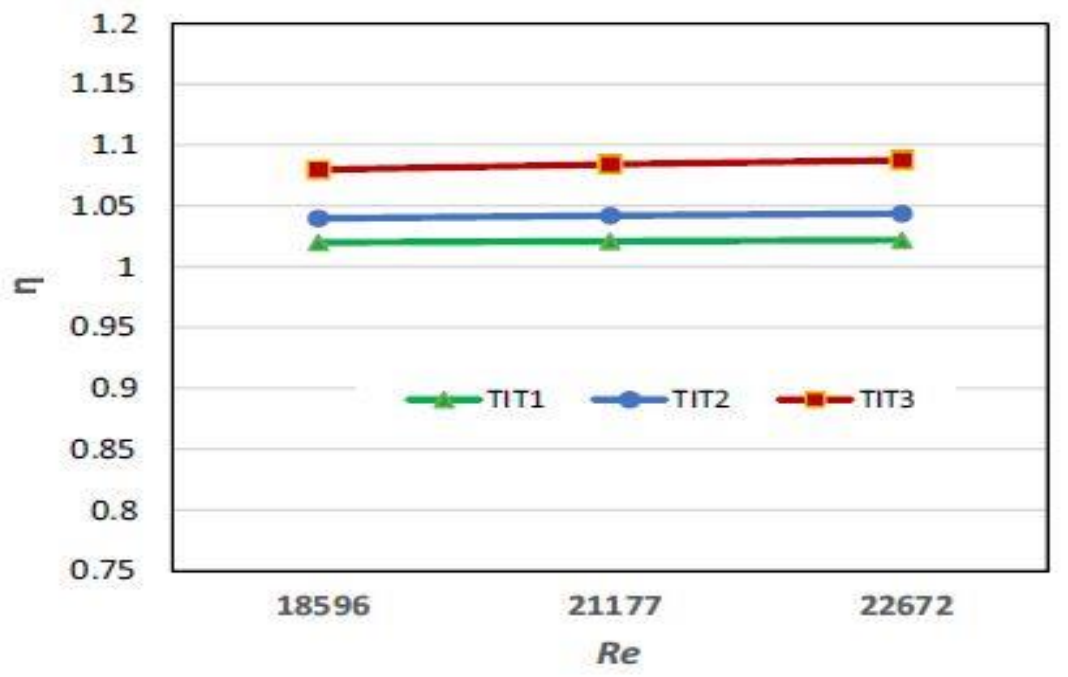

Figure 13: Thermal performance factor Vs Reynolds number for tube inserts [20].

Table 1: Heat transfer enhancement for helical coils with reversed loops and wire coil inserts [21].

\begin{tabular}{|c|c|c|c|c|c|c|c|}
\hline \multirow{3}{*}{$\begin{array}{c}\text { Inlet } \\
\text { Velocity } \\
(\mathrm{m} / \mathrm{s})\end{array}$} & \multirow[t]{3}{*}{$\begin{array}{l}\text { Reynolds } \\
\text { Number }\end{array}$} & \multicolumn{6}{|c|}{$\begin{array}{l}\text { Heat transfer Enhancement Ratio } \\
\qquad=\frac{\text { Heat transfer coefficient of enhanced helical coil loop }}{\text { Heat transfer coefficient of Plain helical coil loop }}\end{array}$} \\
\hline & & \multicolumn{6}{|c|}{ Reversed loop curvature ratio and wire-coil insert pitch } \\
\hline & & $\begin{array}{l}1 / 2 \text { (no insert, } \\
\text { reversed loop } \\
\text { only) }\end{array}$ & $\begin{array}{l}1 / 2 \\
(3 \mathrm{~mm})\end{array}$ & $\begin{array}{l}1 / 2 \\
(20 \mathrm{~mm})\end{array}$ & $\begin{array}{lr}1 / 3 \text { (no } & \text { insert, } \\
\text { reversed loop } \\
\text { only) }\end{array}$ & $\begin{array}{l}1 / 3 \\
(3 \mathrm{~mm})\end{array}$ & $\begin{array}{l}1 / 3 \\
(20 \mathrm{~mm})\end{array}$ \\
\hline 1.5 & 14,037 & 1.04 & 1.09 & 1.04 & 1.04 & 1.1 & 1.07 \\
\hline 1.9 & 17,780 & 1.06 & 1.28 & 1.1 & 1.09 & 1.26 & 1.2 \\
\hline 2.3 & 21,523 & 1.09 & 1.29 & 1.12 & 1.16 & 1.27 & 1.23 \\
\hline 2.7 & 25,266 & 1.12 & 1.23 & 1.11 & 1.17 & 1.22 & 1.18 \\
\hline
\end{tabular}




\subsection{Helical coil insert with ribs}

Virgilioa et al., [22] reveal that the discontinuous rib has a lower impact on the pressure losses on the azimuthal swirl and the turbulent kinetic energy generations, by examining the effects of the discontinuity in the tube corrugations on the flow separations, turbulence statistics, vorticity and strain rates of the flow particles. The investigation also compares them with a previously studied continuous turbulator and found that the changing height of the discontinuous rib generates turbulent kinetic energy and an azimuthal velocity respectively $50 \%$ and $35 \%$ in the field close to the wall which is lower than the continuous configuration. The irregularity of the discontinuous obstacle provides a reduced skin friction coefficient which is 0.57 times lower than previously experimented 2-D helical turbulator. It is also observed that the less intense wall-bounded turbulence level occurs with the 3-D helical turbulator which suggests a lower local heat transfer enhancement [22]. In Figure 14 the schematic of continuous and discontinuous helical turbulators is shown.

\subsection{Air foil-shaped insert}

Gururatana and Skullong [23] was chosen the aerofoil-shaped inserts, modified-NACA0024 to improve the heat transfer performance in the tubes and found that the modified-NACA0024 with an inclination angle of $45^{\circ}$ can provide the best heat transfer enhancement as much as 3 times over the plain tube as well as achieve the maximum heat transfer enhancement performance of 1.45 [23]. Figure 15 is illustrated the geometry of the modified-NACA0024 airfoil-shaped insert.

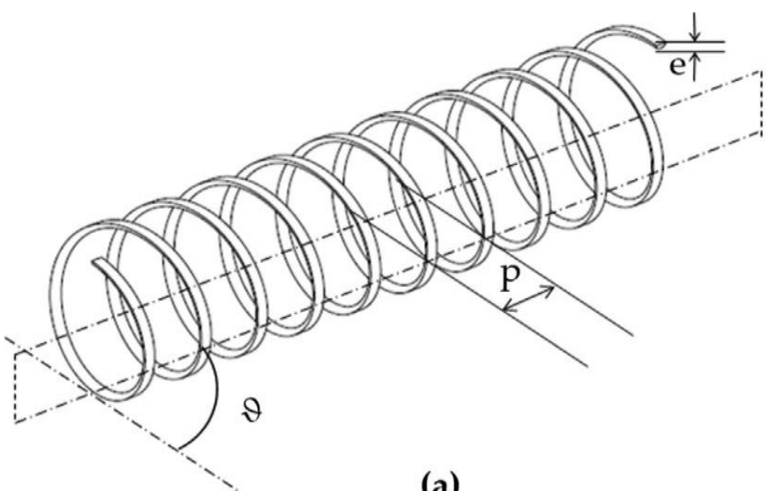

(a)

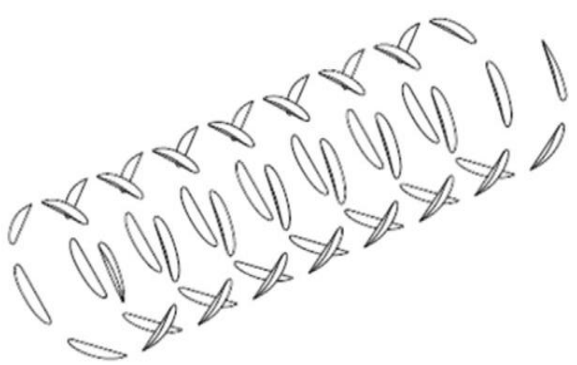

(b)

Figure 14: Schematic of continuous and discontinuous helical turbulators: (a)RIB-1 (b)RIB-2 [22].

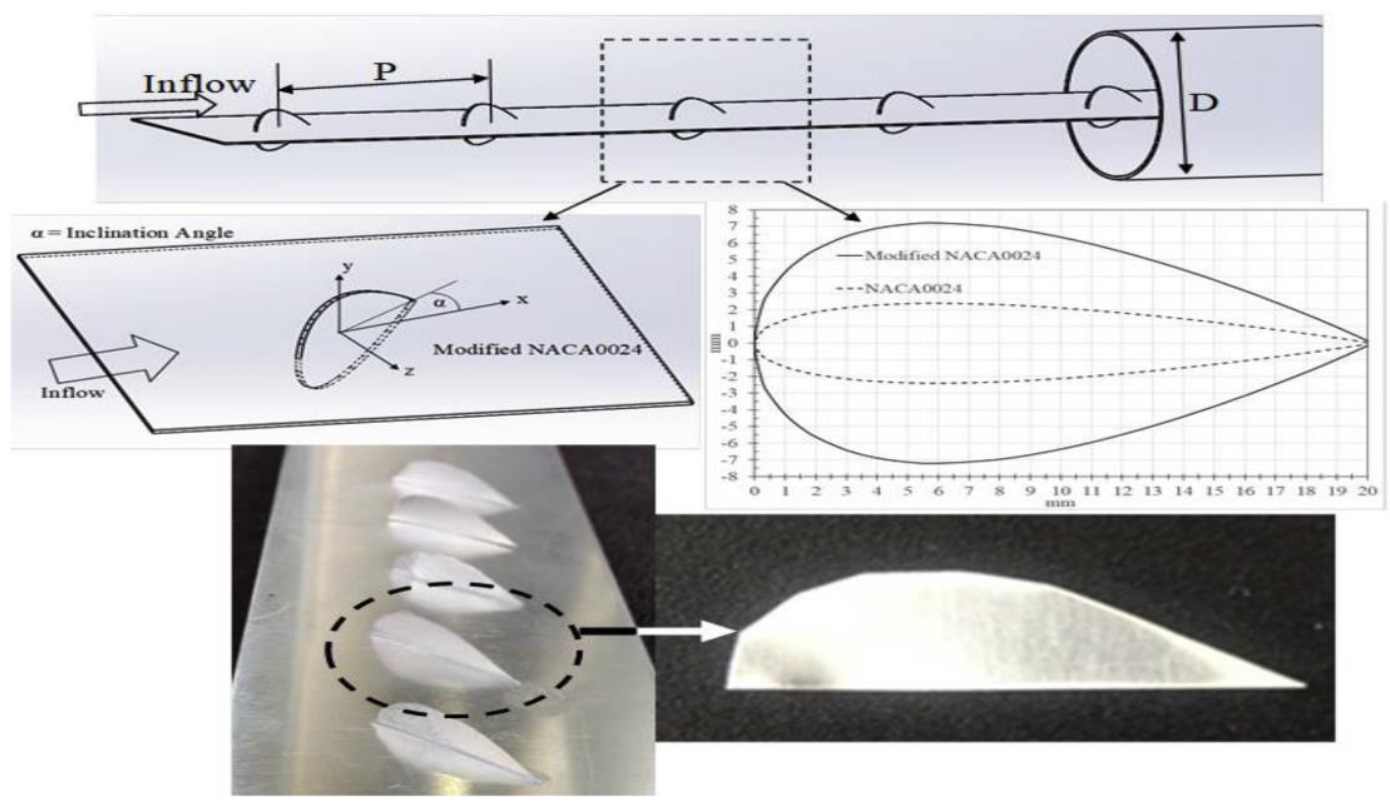

Figure 15: Photograph and geometry of modified-NACA0024 airfoil-shaped insert [23]. 

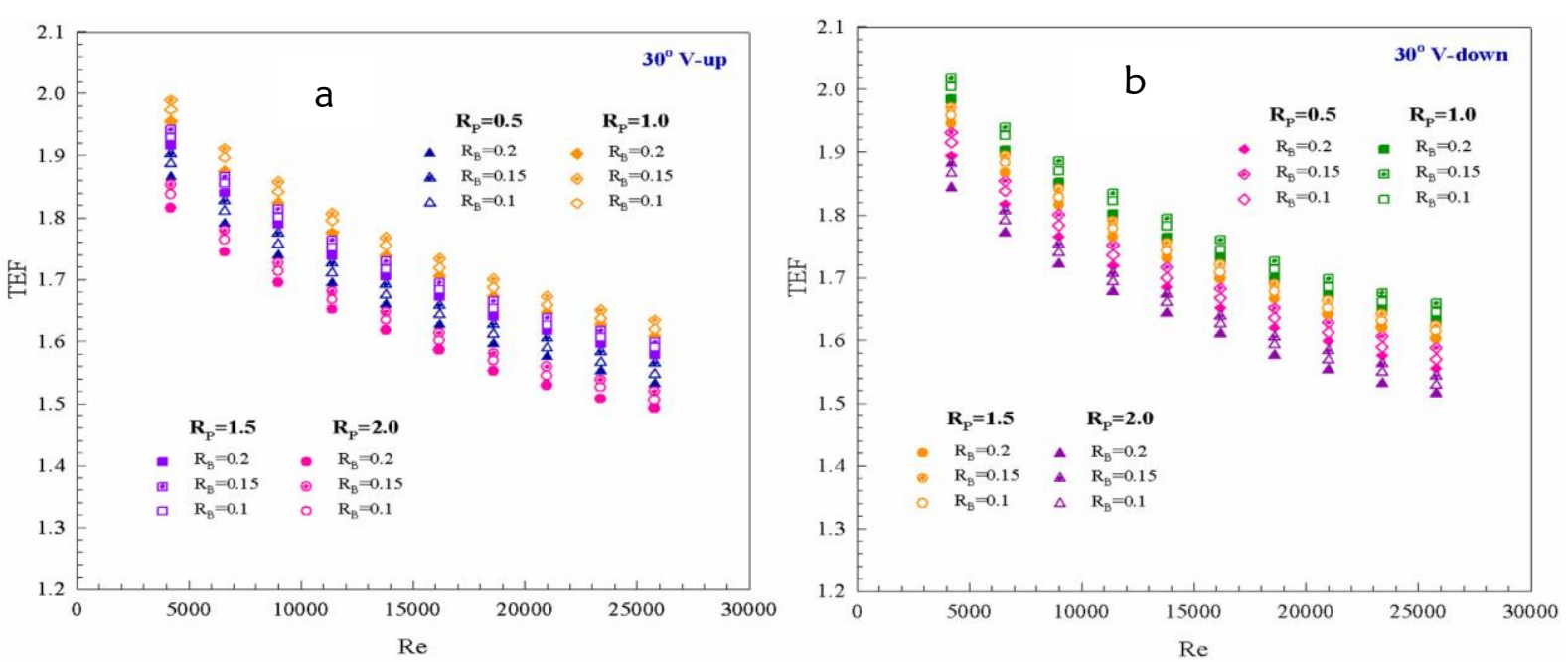

Figure 16: Variation of TEF with Re for (a) V-up DW inserts and (b) V-down DW inserts [24].

\section{$5.3 \mathrm{~V}$-Winglet}

Promvonge et al., [24] have shown that the Discrete- $V$-winglet provides a higher thermal performance enhancement factor compared with the typical $V$-winglets. To explore these findings, a numerical model of the inserted tube flow structures and the heat transfer patterns from the simulation such as temperature contours and streamlines including the Nusselt number contours were proposed by him. It is also observed from this experiment that the $V$-down DW provides a better heat transfer and the thermal performance enhancement factor than the $V$-up one is around $3.6 \%$ and $1.6 \%$ respectively [24]. Figure $16(\mathrm{a})$ and Figure 16(a) illustrates the variation of thermal performance enhancement factor with Re for V-up DW inserts and V-down DW inserts, respectively.

\section{COMBINATION OF NANOFLUID WITH DIFFERENT TYPES OF INSERT}

Some researchers enhance the heat transfer rates in various thermal systems by combining two passive techniques like nanofluids and inserts. Rashidi et al., [25] worked regarding in this issues for heat transfer improvement where a combination of nanofluid with twisted tapes, wire coils, baffles, and vortex generators showed that the vortex generator is more effective compared with nanofluids on the efficiency of plate-fin heat exchangers and wire coil with the sharp-edged shoe has superior heat transfer efficiency in comparison with the circular one, as well as nanofluid has significant heat transfer efficiency when employed with thicker twisted strips and it is better to employ helical baffles with a small helix angle to achieve maximum enhance heat transfer [25].

\subsection{Nanofluids with twisted tape inserts}

Twisted tapes can be widely utilized in the tube due to their significant impact to enhance the heat transfer and thermal performance characteristics. It should be pointed out that by coupling the twisted tapes and nanofluid has a significant potential to achieve the combined advantages of enhancement. by employing twisted tapes with nanoparticles as base fluid and increase liquid mixing and improve the heat transfer enhancement. Some scientists conduct various numerical and experimental works to achieve higher values of heat transfer performance by combining these methods and found nanofluids have superior heat transfer efficiency when employed with thicker twisted strips [25].

\subsection{Nanofluids with wire coil insert}

As a turbulent promoter, wire coils can be used to enhance the turbulence of the working fluids and shows a larger value of the heat transfer rate. Wire coils operate as artificial roughness at larger values of the Reynolds numbers. They are reliable in terms of hot spots and corrosion effects and their performance depends on their geometry and the considered flow regime. This is also observed from the study that more enhancement can be achieved in the heat transfer rates on nanofluids, by using a wire coil inserts with a larger diameter [25].

\subsection{Nanofluids with baffles}

Initially, helical baffles are introduced as a replacement for segmental types insert. The main function of baffles is to interrupt both hydrodynamic and thermal boundary layers as well as improve heat transfer performance. Many researchers studied the combined impact of baffles and nanofluids in the field of thermal efficiencies and found that the baffles can achieve high heat transfer rates and small pressure drops when using in nanofluid combinedly with a small helix angle. It is also observed that a small displacement of the baffles influences the flow and temperature fields [25]. 


\subsection{Nanofluids with vortex generators}

Vortex generators can be used to influence the flow field and the boundary layer development as well as create swirl flow and transfer a great fluid between the center and the wall of the tube, causing a significant heat transfer between the flow and the tube surfaces. It is observed that the vortex generator is more effective in comparison with the nanofluids on the efficiency of plate-fin heat exchangers. Figure 17 shows the different kinds of vortex generators [25].

\section{SUMMARY}

Different types of insert devices are studied regarding their enhancement performance with thermal characteristics in this paper. Some of those are applied individually and some are applied with nanofluids or different arrangements. To figure out the heat transfer enhancement performance of insert devices, it is convenient to represent it in a table with some graphical illustrations. Table 2 shows the observation of recent investigations on various types of insert devices in terms of heat transfer enhancement and their impacts on thermal performance characteristics in different flow and mediums, and it is found that a small variation of thermal properties can influence the heat transfer rate whereas the geometry of the insert tube needs a considerable change to enhance the heat transfer rates. It also appeared that the spacing between insert devices, twist ratios, width ratios, and flow conditions of the medium influence the performance of enhancement characteristics. It is considered that twisted tape insert mixes the bulk flow well and therefore, performs better in a laminar flow than turbulent flow. Compared to the wire coil, the twisted tape is not effective in the turbulent flow because it blocks the flow and creates a large pressure drop. Hence, the thermo-hydraulic performance of a twisted tape is not good compared with a wire coil in a turbulent flow. Therefore, it may be concluded that, for compact heat exchanger design, a wire coil is a good choice in a turbulent flow. However, the other several passive techniques such as baffles, winglets and airfoil-shaped insert, etc. are generally more efficient in the turbulent flow than in the laminar flow.

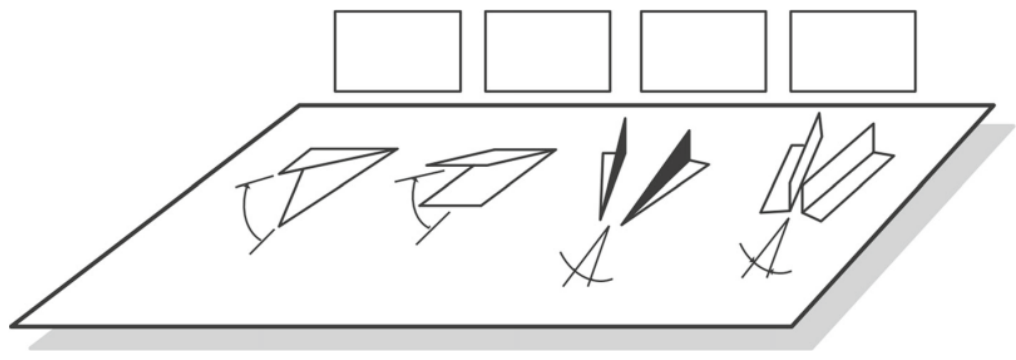

Figure 17: Different kinds of vortex generators: delta wing, rectangular wing, delta winglet pair and rectangular winglet pair [25].

Table 2: Observation of recent investigations on various types of insert device in terms of heat transfer enhancement.

\begin{tabular}{|c|c|c|c|c|}
\hline $\begin{array}{l}\text { Insert } \\
\text { Device }\end{array}$ & $\begin{array}{c}\text { Configuration } \\
\text { with } \\
\text { [Reference] }\end{array}$ & $\begin{array}{l}\text { Working } \\
\text { Fluid }\end{array}$ & Conditions & Observation \\
\hline \multirow[t]{3}{*}{$\begin{array}{c}\text { Twisted } \\
\text { tape inserts }\end{array}$} & $\begin{array}{c}\text { TT (stainless } \\
\text { steel) } \\
{[10]}\end{array}$ & $\begin{array}{c}\text { Hydrocarbon } \\
\text { fuel } \\
\text { (kerosene) }\end{array}$ & $\begin{array}{c}(2700 \leq \mathrm{Re} \\
\leq 20000) \\
\text { Twist ratio }= \\
(6.31,12.63)\end{array}$ & $\begin{array}{l}\text { (1) The average HTC for the TT tube was } \\
\text { approximately } 18 \% \text { larger than that for the } \\
\text { plain tube, as well as the smaller twist ratio was } \\
\text { responsible for excellent fluid mixing and a } \\
\text { higher HTC. }\end{array}$ \\
\hline & $\begin{array}{l}\text { PTTT } \\
\text { [11] }\end{array}$ & Air & $\begin{array}{l}(7,250 \leq \mathrm{Re} \\
\leq 49,800) \\
\text { Porosities= } \\
(1.2,4.6 \\
10.4 \text { and } \\
18.6 \%)\end{array}$ & $\begin{array}{l}\text { (1) PTTT insert with a porosity of } 4.6 \% \text {, } \\
\text { provided the highest heat transfer enhancement } \\
\text { is } 320 \% \text {, highest friction factor which is } 355 \% \\
\text { and maximum TEE of } 1.5 \text { compared to those of } \\
\text { the smooth tubes. }\end{array}$ \\
\hline & $\begin{array}{c}\text { Ribbed tube } \\
\text { with (PT, } \\
\text { FLTT, HLUTT) } \\
{[12]}\end{array}$ & Air & $\begin{array}{c}(25000 \leq \operatorname{Re} \\
\leq 110000)\end{array}$ & $\begin{array}{l}\text { (1) FTTT shows better heat transfer, friction } \\
\text { factor, and enhancement efficiency compared } \\
\text { to HLTT. } \\
\text { (2) Compared to the plain tube with inserts the } \\
\text { heat transfer coefficient of ( } 8-36 \%) \text { was } \\
\text { estimated as higher in the case of HLUTT. } \\
\text { (3) The thermal performance factor decreases }\end{array}$ \\
\hline
\end{tabular}




\begin{tabular}{|c|c|c|c|c|}
\hline & & & & $\begin{array}{l}\text { with an increase in Re and twist ratios in the } \\
\text { case of HLUTT and HLDTT twisted tapes. }\end{array}$ \\
\hline & $\begin{array}{l}\text { Twisted Tapes } \\
\text { (X-shaped and } \\
\text { twisted tape } \\
\text { insert) } \\
\text { [13] }\end{array}$ & Water & $\begin{array}{l}\text { Twist ratio= } \\
(3,4) \text {; Nusselt } \\
\text { Number }= \\
(2.91 \text { to } 5.16 \\
\text { for the } X \text { - } \\
\text { shaped and } \\
2.52 \text { to } 4.46 \\
\text { and } 3.07 \text { to } \\
5.33 \text { for } \\
\text { constant and } \\
\text { variable } \\
\text { pitch twisted } \\
\text { tape) }\end{array}$ & $\begin{array}{l}\text { (1) The X-shaped tape inserts showed significant } \\
\text { high heat transfer rates of } 1.27 \text { and } 1.08 \text { times } \\
\text { greater in comparison with the constant pitch } \\
\text { and variable pitch twisted tape inserts. } \\
\text { (2) To enhance the heat transfer characteristics } \\
\text { and thermal performance of the heat } \\
\text { exchangers, turbulence intensity and swirl flow } \\
\text { of the fluid near the wall surface consider as } \\
\text { significant factors. } \\
\text { (3) To enhance the overall performance of the } \\
\text { heat exchanger, effective geometry is essential } \\
\text { because of the increments in the turbulence } \\
\text { intensity caused by the X-shaped tape inserts. }\end{array}$ \\
\hline & $\begin{array}{c}\text { Sparsely placed } \\
\text { twisted tapes } \\
{[14]}\end{array}$ & Air & $\begin{array}{l}(6000 \leq \\
\text { Re } \leq 22000) \\
\text { Twist Ratio } \\
(2.0,2.5,3.0 \\
\text { and 3.5) }\end{array}$ & $\begin{array}{l}\text { (1) Sparsely placed twisted tapes installed with } \\
\text { multiple transverse twisted baffles showing the } \\
\text { maximum thermal performance factor of } 1.32 \\
\text { at a Reynolds number of } 6000 \text {, twist ratio of } \\
3.5 \text {, and width ratio of } 0.22 \text {. }\end{array}$ \\
\hline & $\begin{array}{c}\text { Double-sided } \\
\text { delta-wing } \\
\text { tape insert } \\
{[15]}\end{array}$ & Water & $\begin{array}{c}(5300 \leq \mathrm{Re} \\
\leq 14500) \\
\text { Pitch Ratio }= \\
1.18\end{array}$ & $\begin{array}{l}\text { (1) T-W inserts with a PNW of } 1.18 \text { produces the } \\
\text { greatest thermal performance factor of } 1.15 \text {. } \\
\text { (2) T-W inserts with a PNW of } 1.18 \text { offer the } \\
\text { highest average Nusselt number of } 177 \% \\
\text { compared to a plain tube. } \\
\text { (3) The tube having T-W inserts with PNW of } \\
1.18 \text { produces the highest friction factor, which } \\
\text { is } 11.6 \text { and } 2.72 \text { times greater than the plain } \\
\text { tube. }\end{array}$ \\
\hline & $\begin{array}{c}\text { Segmented } \\
\text { twisted } \\
\text { tape Insert } \\
{[16]}\end{array}$ & Air & $\begin{array}{l}(10000 \leq \mathrm{Re} \\
\leq \quad 35000) \\
\text { Twist ratio }= \\
(2.0,3.3 \text { and } \\
\quad 4.6) \\
\text { Length ratio } \\
=(0.3,0.5 \\
\text { and } 0.7)\end{array}$ & $\begin{array}{l}\text { (1) Segmented twisted tapes can increase the } \\
\text { local heat transfer coefficient up to } 2.8 \text {. } \\
\text { (2) Twist ratio plays a more critical role in local } \\
\text { heat transfer enhancement over length ratio, } \\
\text { and a smaller twist ratio usually has a better } \\
\text { performance. }\end{array}$ \\
\hline & $\begin{array}{c}\text { Helical tube } \\
\text { with twisted } \\
\text { tape insert } \\
{[17]}\end{array}$ & Air, Water & $\begin{array}{c}(100 \leq \operatorname{Re} \leq \\
2000)\end{array}$ & $\begin{array}{l}\text { (1) Twisted tape inserts with helical tube heat } \\
\text { exchanger at a higher frictional pressure drop } \\
\text { conditions show } 4 \text { times enhanced heat transfer } \\
\text { performance compared to the conventional } \\
\text { straight tube heat exchanger. }\end{array}$ \\
\hline $\begin{array}{l}\text { Wire-coil } \\
\text { inserts }\end{array}$ & $\begin{array}{c}\text { Wire-coil Insert } \\
{[18]}\end{array}$ & Air & $\begin{array}{l}\text { Twist ratios } \\
=(3.5,2.66 \\
\text { and } 2.25) \\
\text { Pitch ratio }= \\
\quad 0.88\end{array}$ & $\begin{array}{l}\text { (1) The higher heat transfer can be achieved by } \\
\text { using wire coils inserts instead of a smooth one. } \\
\text { (2) Copper has a higher thermal conductivity of } \\
94 \% \text { than brass ( } 66 \%) \text { and aluminum ( } 91 \%) \text { as } \\
\text { a wire coil Insert. }\end{array}$ \\
\hline & $\begin{array}{c}\text { Wire-coil Insert } \\
{[19]}\end{array}$ & Air & $\begin{array}{c}(6000 \leq \mathrm{Re} \leq \\
22000) ; \\
\text { Pitches }=12, \\
24,40, \text { and } \\
50 \mathrm{~mm} \text { with } \\
\text { correspondin } \\
\text { g helix angles } \\
=10^{\circ}, 20^{\circ}, \\
35^{\circ} \text {, and } 45^{\circ}, \\
\text { respectively }\end{array}$ & $\begin{array}{l}\text { (1) The friction factor for the wire coil inserted } \\
\text { tubes becomes as much as } 4 \text { times higher than } \\
\text { smooth tubes, for comparable Reynolds } \\
\text { numbers. } \\
\text { (2) For similar flow conditions, the average } \\
\text { heat transfer coefficient for tubes with a wire } \\
\text { coil inserts increase } 2 \text { times than the smooth } \\
\text { tubes. } \\
\text { (3) The heat transfer effectiveness for the wire- } \\
\text { coil inserted tubes increases as much as } 1.25 \\
\text { times than that of the smooth tubes, for } \\
\text { comparable Reynolds numbers. }\end{array}$ \\
\hline
\end{tabular}




\begin{tabular}{|c|c|c|c|c|}
\hline & $\begin{array}{c}\text { Wire-coil Insert } \\
{[20]}\end{array}$ & $\begin{array}{l}\mathrm{Al}_{2} \mathrm{O}_{3}-\mathrm{EC} \\
\text { nanofluid }\end{array}$ & $\begin{array}{l}(18500<\operatorname{Re} \\
<22700) \\
\text { (Concentrati } \\
\text { ons of } \\
\text { nanofluid= } \\
0.08 \% \\
0.5 \% \text { and } \\
1 \% \text { ) }\end{array}$ & $\begin{array}{l}\text { (1) The wire coil inserts with the nanofluid with } \\
\text { a concentration of } 0.08 \%, 0.5 \% \text { and } 1 \% \\
\text { results the thermal performance enhancement } \\
\text { up to } 5 \% \text { as compared to the use of coils } \\
\text { inserts alone. } \\
\text { (2) The values of thermal performance factors } \\
\text { are not significantly different for different cases } \\
\text { of Reynolds number. }\end{array}$ \\
\hline & $\begin{array}{l}\text { Helical coils } \\
\text { with wire coil } \\
\text { Insert } \\
\text { [21] }\end{array}$ & Water & $\begin{array}{c}(6000<\operatorname{Re} \\
<27000)\end{array}$ & $\begin{array}{l}\text { (1) The structural modifications of the } \\
\text { conventional helical coil with wire coil insert } \\
\text { configuration led to better thermal } \\
\text { performance while the pressure drop increased } \\
\text { slightly up to } 115 \% \text { with curvature ratios. }\end{array}$ \\
\hline \multirow[t]{3}{*}{$\begin{array}{l}\text { Other } \\
\text { types of } \\
\text { inserts }\end{array}$} & $\begin{array}{l}\text { 2-D and 3-D } \\
\text { helical inserts } \\
\quad[22]\end{array}$ & Water & $\begin{array}{l}20000<\mathrm{Re} \\
<80000) \\
\text { Pitch to } \\
\text { diameter } \\
\text { ratio }=11 \\
\text { Height to } \\
\text { diameter } \\
\text { ratio }= \\
3.6 \%\end{array}$ & $\begin{array}{l}\text { (1) Friction coefficients of the continuous and } \\
\text { discontinuous turbulators are respectively } 7 \text { and } \\
4 \text { times higher than the case of a smooth pipe. } \\
\text { (2) Compared to previously experimented 2-D } \\
\text { helical turbulator the irregularity of the } \\
\text { discontinuous obstacles provides a } 0.57 \text { times } \\
\text { lower skin friction coefficient. } \\
\text { (3) The 3-D helical turbulator suggests a lower } \\
\text { local heat transfer enhancement when less } \\
\text { intense wall-bounded turbulence occurs. }\end{array}$ \\
\hline & $\begin{array}{l}\text { Airfoil-shaped } \\
\text { insert, } \\
\text { (Modified } \\
\text { NACA0024) } \\
\text { [23] } \\
\end{array}$ & Air & $\begin{array}{l}(4196<\mathrm{Re} \\
<8125) \\
\text { Inclination } \\
\text { angle }=\left(0^{\circ}\right. \\
\left.30^{\circ} \text { and } 45^{\circ}\right)\end{array}$ & $\begin{array}{l}\text { (1) The modified NACAOO24 with an } \\
\text { inclination angle of } 45^{\circ} \text { is showed the most } \\
\text { effectiveness and the maximum heat transfer } \\
\text { enhancement performance of } 1.45 \text {. }\end{array}$ \\
\hline & $\begin{array}{l}\text { Discrete- } V \\
\text { winglet tape } \\
\text { [24] }\end{array}$ & Air & $\begin{array}{l}(4200<\mathrm{Re} \\
<25800) \\
\text { Winglet pitch } \\
=(0.5,1.0 \\
\quad 1.5 \\
\text { and } 2.0)\end{array}$ & $\begin{array}{l}\text { (1) The discrete- } V \text { winglet tape (DW) provides a } \\
\text { considerable heat transfer enhancement in the } \\
\text { tubes. } \\
\text { (2) Compared to } V \text {-up DW, the } V \text {-down DW } \\
\text { provides better heat transfer and thermal- } \\
\text { performance enhancement factor which is } 1.6 \% \\
\text { and } 3.6 \% \text { respectively. }\end{array}$ \\
\hline \multirow[t]{4}{*}{$\begin{array}{l}\text { Nanofluids } \\
\text { with } \\
\text { different } \\
\text { types of } \\
\text { Inserts }\end{array}$} & $\begin{array}{l}\text { Combination } \\
\text { of nanofluids } \\
\text { and twisted } \\
\text { tape inserts } \\
\text { [25] }\end{array}$ & $\begin{array}{l}\text { Nanofluid } \\
\left(\mathrm{Al}_{2} \mathrm{O}_{3}, \mathrm{CuO}\right. \\
\mathrm{TiO}_{2} \text { and } \\
\text { CNT with } \\
\text { water })\end{array}$ & $\begin{array}{c}(100<\operatorname{Re}< \\
30,000)\end{array}$ & $\begin{array}{l}\text { (1) Nanofluids have superior heat transfer } \\
\text { efficiency when employed with thicker twisted } \\
\text { strips. } \\
\text { (2) Twisted tape with alternated axis has a } \\
\text { larger value of heat transfer of } 89 \% \text { as } \\
\text { compared with the case of ordinary twisted } \\
\text { tapes. }\end{array}$ \\
\hline & $\begin{array}{l}\text { Combination } \\
\text { of nanofluids } \\
\text { and wire coil } \\
\text { insert } \\
\text { [25] }\end{array}$ & $\begin{array}{l}\text { Nanofluid } \\
\left(\mathrm{Fe}_{3} \mathrm{O}_{4}\right. \\
\mathrm{Al}_{2} \mathrm{O}_{3}, \mathrm{CuO} \\
\text { and } \\
\text { grapheme } \\
\text { oxide-water) }\end{array}$ & $\begin{array}{c}(10<\operatorname{Re}< \\
22,700)\end{array}$ & $\begin{array}{l}\text { (1) More improvement can be achieved in the } \\
\text { heat transfer rates on nanofluids by using a } \\
\text { wire coil with a larger diameter. } \\
\text { (2) Wire coil inserts with grapheme oxide-- } \\
\text { water nanofluid improves the heat transfer rate } \\
\text { up to } 77 \% \text {. }\end{array}$ \\
\hline & $\begin{array}{l}\text { Combination } \\
\text { of nanofluids } \\
\text { and baffles } \\
{[25]}\end{array}$ & $\begin{array}{l}\text { Nanofluid } \\
\left(\mathrm{Al}_{2} \mathrm{O}_{3}, \mathrm{CuO}\right. \\
\mathrm{TiO}_{2} \text { and } \\
\text { CNT with } \\
\text { water })\end{array}$ & $\begin{array}{c}(50<\mathrm{Re}< \\
15,000)\end{array}$ & $\begin{array}{l}\text { (1) A small displacement of the baffle leads to } \\
\text { an intense change in the flow and temperature } \\
\text { fields. It is better to employ helical baffles with } \\
\text { a small helix angle to achieve a high heat } \\
\text { transfer rate of } 255 \% \text { and small pressure } \\
\text { drops. }\end{array}$ \\
\hline & $\begin{array}{c}\text { Vortex } \\
\text { generators } \\
{[25]}\end{array}$ & $\begin{array}{l}\text { Nanofluid } \\
\left(\mathrm{Al}_{2} \mathrm{O}_{3}, \mathrm{Cu}\right. \\
\text { and } \mathrm{TiO}_{2} \\
\text { with water) }\end{array}$ & $\begin{array}{c}(50<\operatorname{Re}< \\
12,200)\end{array}$ & $\begin{array}{l}\text { (1) The usage of a vortex generator is more } \\
\text { effective in comparison with the nanofluid on } \\
\text { the efficiency of plate-fin heat exchangers. } \\
\text { (2) Employing nanofluid with a vortex } \\
\text { generator can enhance the performance of up } \\
\text { to } 27 \% \text {. }\end{array}$ \\
\hline
\end{tabular}


To summarize the above observations, different insert devices have been classified into four major categories of inserts such as twisted tape inserts, wire coil inserts, other types of inserts and nanofluids with inserts. In each category, there are also two or more sub-elements classified according to the geometry or names of the inserts. By analyzing the above results of different researchers, Table 3 shows the important findings of thermal performance characteristics and heat transfer enhancement of different insert devices with suitable geometrical conditions. To observe the impact on performance characteristics of heat transfer enhancement it is found that X-shaped tape insert shows 27.7 times greater friction factor compared to a smooth tube with an equivalence heat transfer enhancement of $355 \%$. On the other hand, the wire coil insert with a reverse loop arrangement shows the highest pressure drop of $115 \%$ and twisted tapes include helical tube shows 0.35 of pressure drop factor with 4 times enhancement performance.

The heat transfer enhancements of these insert devices compare to the smooth tube are illustrated in Figure 18 to figure out the maximum performance of heat transfer enhancement achieved by various scientists by using different types of insert devices in different conditions. An equivalent heat transfer enhancement parameter of these insert devices is considered to compare the corresponding inserts enhancement performance with smooth tubes and found that the twisted tape with helical tube shows the highest equivalence heat transfer enhancement of $400 \%$. As an effective geometry of tape inserts, the $\mathrm{X}$-shaped tape insert shows the second-highest equivalent heat transfer enhancement of $355 \%$ whereas the wire coil insert shows the least performance of $9 \%$ compares to a smooth tube without any use of insert devices.

The graphical representation of the above findings is illustrated in Figure 19, and it is observed that compared to identical inserts without any nanofluids it can be achieved up to $255 \%, 89 \%, 77 \%$, and $27 \%$ of equivalence heat transfer enhancement by baffles, twisted tapes, wire coils, and vortex generator, respectively when using with nanofluids as a flow medium.

Table 3: Important findings of literature reviews regarding the heat transfer enhancement with various insert devices compared to smooth tubes.

\begin{tabular}{|c|c|c|c|c|c|c|c|c|c|c|}
\hline $\begin{array}{c}\text { Insert } \\
\text { Devices }\end{array}$ & Geometry & $\mathrm{FF}$ & PD & HTC & HTE & HTR & HTP & TEF & $\begin{array}{c}\text { HTE } \\
\text { Equivalence } \\
\text { to Smooth } \\
\text { surface } \\
\end{array}$ & Reference \\
\hline \multirow{7}{*}{$\begin{array}{l}\text { Twisted } \\
\text { Tape } \\
\text { Insert }\end{array}$} & TT & & & $18 \%$ & & & & & $18 \%$ & [10] \\
\hline & PTTT & $355 \%$ & & & $320 \%$ & & & 1.5 & $320 \%$ & [11] \\
\hline & $\begin{array}{l}\text { X-shaped } \\
\text { tape insert }\end{array}$ & $\begin{array}{l}27.7 \\
\text { times }\end{array}$ & & & & $\begin{array}{l}3.55 \\
\text { times }\end{array}$ & & & $355 \%$ & [13] \\
\hline & $\begin{array}{c}\text { Sparsely } \\
\text { placed TT } \\
\text { with } \\
\text { baffles }\end{array}$ & & & & & $\begin{array}{l}2.52 \\
\text { times }\end{array}$ & 1.32 & & $252 \%$ & [14] \\
\hline & $\begin{array}{l}\text { T-W } \\
\text { inserts }\end{array}$ & & & & & & 11.5 & & & [15] \\
\hline & $\begin{array}{c}\text { Segmented } \\
\text { twisted } \\
\text { tapes }\end{array}$ & $235 \%$ & & $\begin{array}{c}2.8 \\
\text { times }\end{array}$ & & $235 \%$ & & & $235 \%$ & [16] \\
\hline & $\begin{array}{l}\text { TT with } \\
\text { helical } \\
\text { tube }\end{array}$ & & 0.35 & & & & $\begin{array}{c}4 \\
\text { times }\end{array}$ & & $400 \%$ & [17] \\
\hline \multirow{3}{*}{$\begin{array}{l}\text { Wire } \\
\text { coil } \\
\text { Insert }\end{array}$} & Wire coil & 4 folds & & $\begin{array}{c}2 \\
\text { folds }\end{array}$ & 1.25 & & & & & [19] \\
\hline & Wire coil & $11.18 \%$ & & & & $9 \%$ & $5 \%$ & & $9 \%$ & [20] \\
\hline & $\begin{array}{l}\text { Wire coil } \\
\text { (Reversed } \\
\text { loops) }\end{array}$ & & $115 \%$ & & & & & & & [21] \\
\hline \multirow{3}{*}{$\begin{array}{l}\text { Other } \\
\text { types } \\
\text { of } \\
\text { inserts }\end{array}$} & $\begin{array}{l}\text { Helical } \\
\text { Insert }\end{array}$ & $\begin{array}{c}7 \\
\text { times }\end{array}$ & & & & & & & & [22] \\
\hline & $\begin{array}{c}\text { Air-foil } \\
\text { shaped } \\
\text { insert }\end{array}$ & & & & $\begin{array}{c}3 \\
\text { times }\end{array}$ & & 1.45 & & $300 \%$ & [23] \\
\hline & $\begin{array}{c}\text { Discrete-V } \\
\text { winglet } \\
\text { tape } \\
\text { (Down) }\end{array}$ & & & & & & & 2.02 & & [24] \\
\hline
\end{tabular}


Table 4 depicts another important finding from literature reviews regarding the heat transfer enhancement and thermal characteristics of various insert devices with a combination of nanofluids which is compared with the corresponding insert device alone. It is noticed that the twisted tape inserts achieved the friction factor of 23.69 with $89 \%$ enhancement of heat transfer whereas helical baffles with small helix angle achieved the highest equivalence heat transfer enhancement of $255 \%$ as well as $150 \%$ pressure drops compare to inserts without nanofluids arrangement.

Comparative graphical representation of equivalence heat transfer enhancement among four major classifications of the insert device is illustrated in Figure 20. As can be seen from the figure the twisted tape inserts have the highest heat transfer enhancement of $400 \%$ followed by that for air-foil shaped inserts having a value of $300 \%$ followed by that for nanofluids with baffles having a value of $255 \%$ followed by that for wire coil having a value of $9 \%$.

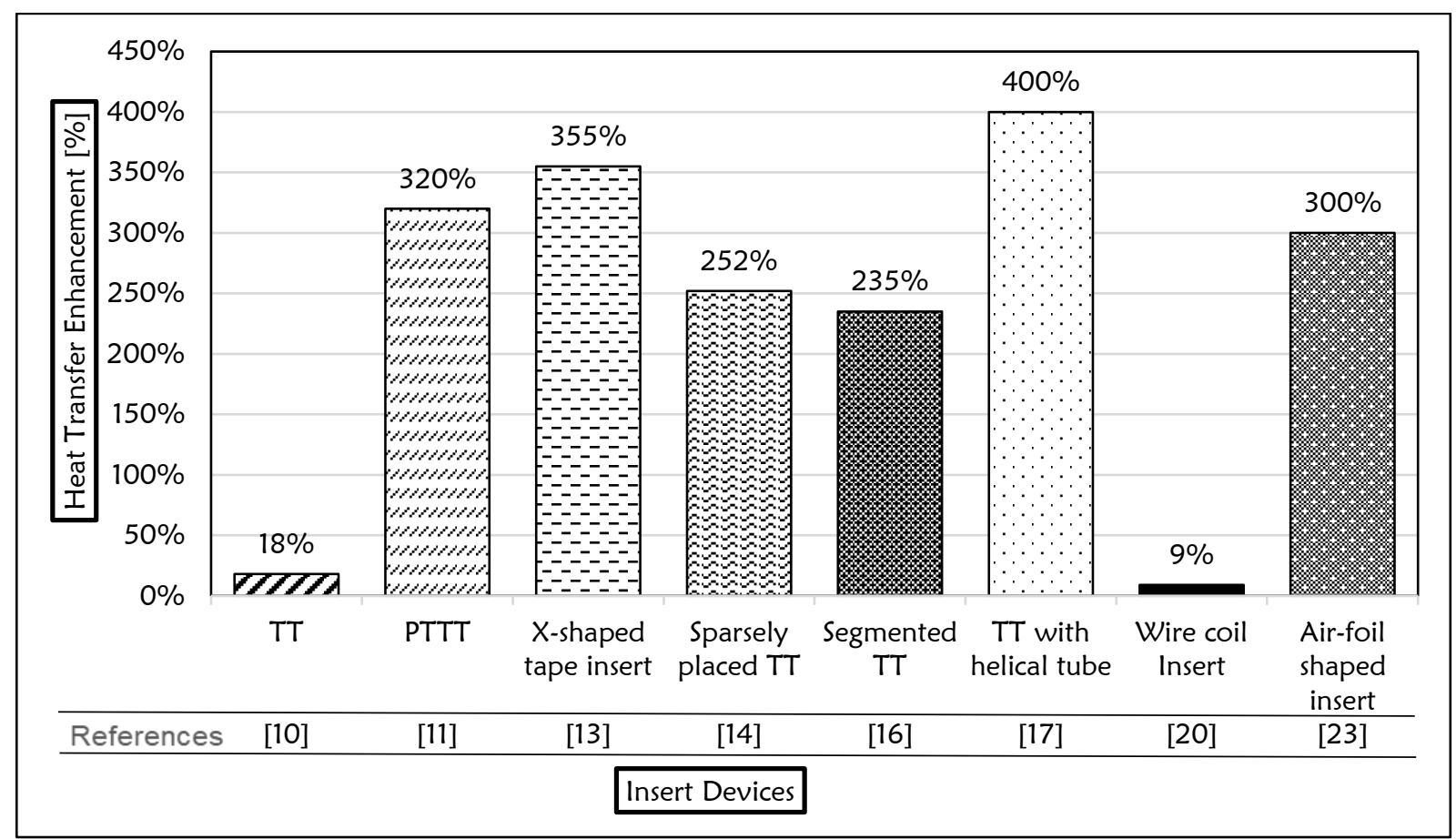

Figure 18: Equivalent percentage of heat transfer enhancement with different insert devices.

Table 4: Important findings of literature reviews regarding the heat transfer enhancement of various insert devices with nanofluids compared to the corresponding insert device alone.

\begin{tabular}{cccccccc}
\hline $\begin{array}{c}\text { Insert Devices with } \\
\text { Nanofluids }\end{array}$ & FF & PD & HTC & HTE & HTR & HTP & $\begin{array}{c}\text { TTEF } \\
\text { Equivalence } \\
\text { for } \\
\text { Nanofluid }\end{array}$ \\
\hline Twisted tape & 23.69 & & & & $89 \%$ & $89 \%$ & {$[25]$} \\
Wire coil & & & & $77 \%$ & $77 \%$ & {$[25]$} \\
Baffles & $150 \%$ & $255 \%$ & & & $255 \%$ & {$[25]$} \\
Vortex generator & $8.50 \%$ & & & $27 \%$ & $27 \%$ & {$[25]$} \\
\hline
\end{tabular}




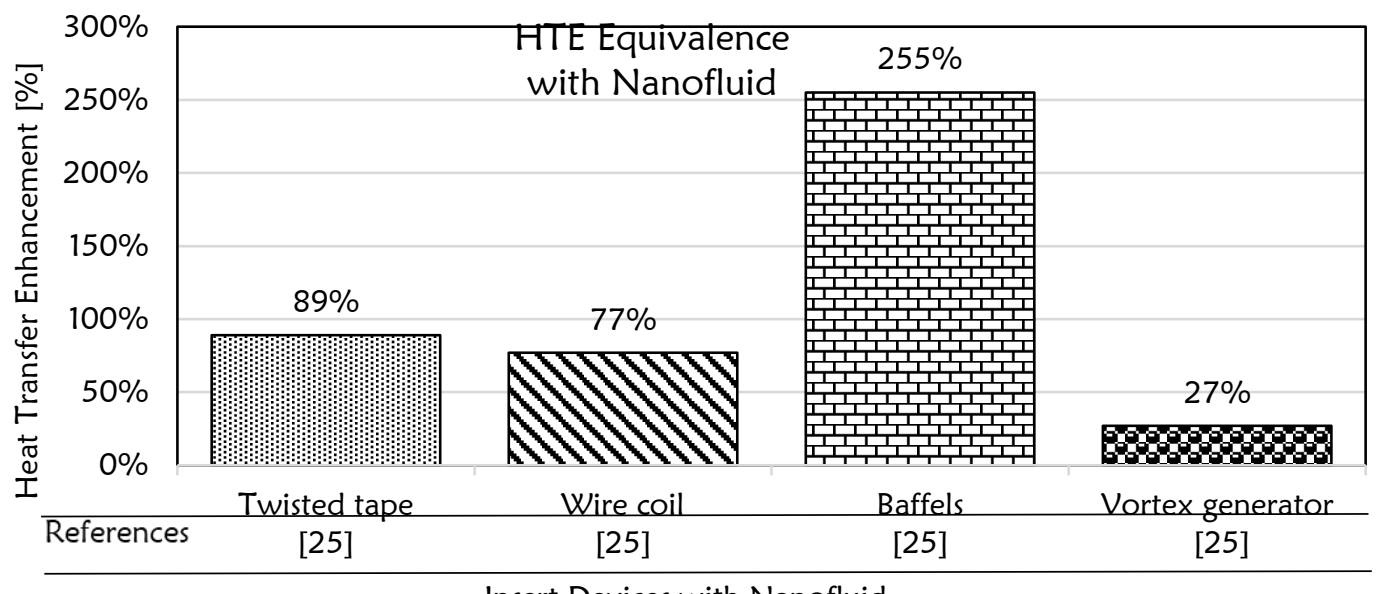

Insert Devices with Nanofluid

Figure 19: The equivalence heat transfer enhancement of various insert devices with nanofluid compared to identical insert devices without nanofluids.

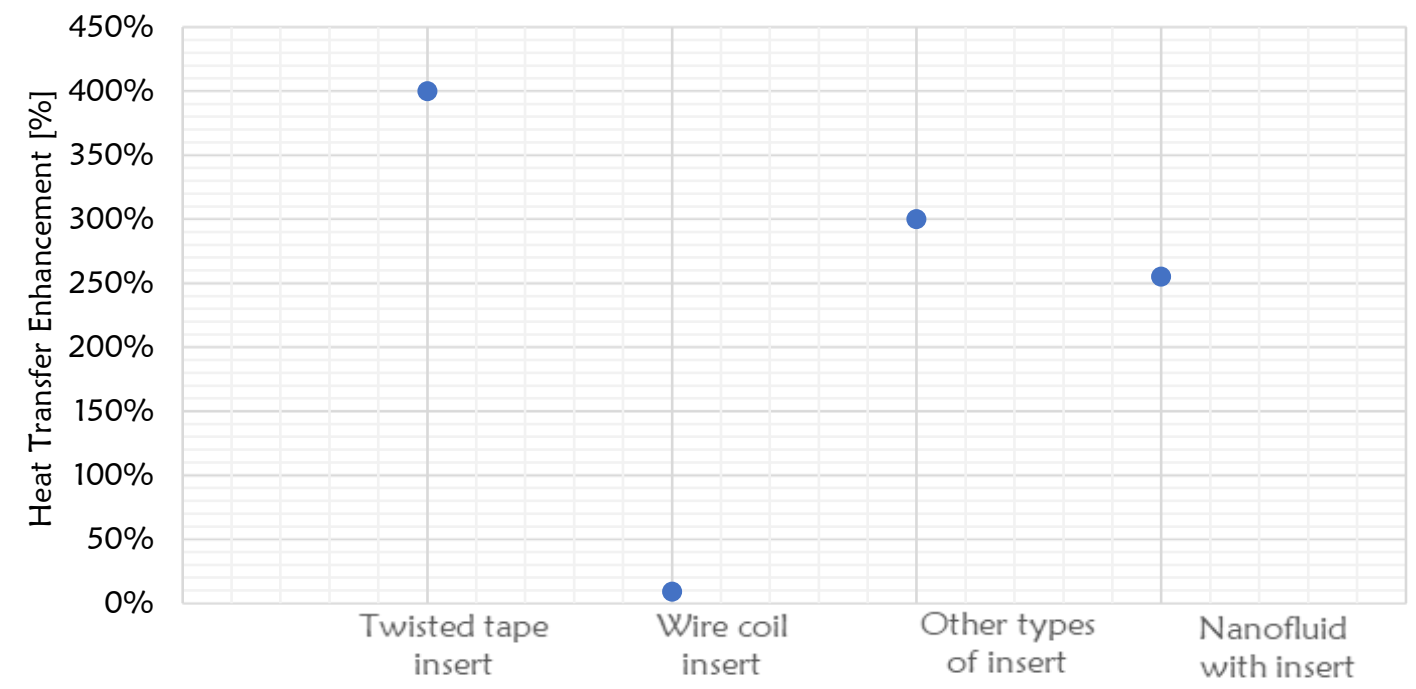

Insert Devices

Figure 20: Comparative representation of heat transfer enhancement by classified inserts.

\section{CONCLUSIONS}

The study about the effect of inserts on heat transfer characteristics has been reviewed. Different types of inserts in various conditions and arrangements have been considered. The main conclusions can be briefly drawn as follows.

1) To enhance the heat transfer characteristics and thermal performance of the heat exchangers turbulence intensity and swirl flow of the fluid near the wall surface consider as significant factors. Effective geometry is another important condition to enhance the overall performance which can able to increase the turbulence intensity caused by various insert devices like twisted tapes. The twist ratio of the twisted tape plays a significant role in local heat transfer enhancement over length ratio and smaller twist ratio generally responsible for excellent fluid mixing as well as better performance. From the above information, it can be inferred that due to turbulence intensity and swirl flow of the fluid near the wall surface twisted tape with a helical tube at a frictional pressure drop of 0.35 can enhance the maximum equivalent heat transfer rate up to $400 \%$. Moreover, tubes with PTTT, X-shaped tape insert, sparsely placed TT, segmented TT also enhance the equivalent percentage of heat transfer up to $320 \%, 355 \%, 252 \%$ and $235 \%$ respectively, compared to smooth tubes. 
2) Wire coil inserts have several advantages compared to other enhancement techniques because of its geometry and easer applications. The heat transfer effectiveness for the wire coil inserted tubes increases as much as 1.25 times than that of the smooth tube for comparable Reynolds numbers whereas the coil inserts with the nanofluid with a concentration of $0.08 \%, 0.5 \%$, and $1 \%$ results in the thermal performance enhancement up to $5 \%$ as compared to the use of coils inserts alone. In addition, the structural modifications of the conventional helical coil with a wire coil insert configuration led to better thermal performance while the pressure drop increased up to $115 \%$ with the curvature ratio. The literature found that the wire coil inserts can achieve as maximum as $9 \%$ of equivalence heat transfer enhancement with $11.18 \%$ of friction factor.

3) Helical inserts, DW and air-foil shaped inserts are another significant insert device in the field of heat transfer enhancement. As an enhancer, friction coefficients of the continuous and discontinuous helical inserts are respectively 7 and 4 times higher than the case of smooth tubes. Compared to V-up DW, the V-down DW provides better heat transfer and thermal performance enhancement up to $1.6 \%$ and $3.6 \%$ respectively. Moreover, the modified air-foil shaped insert with an inclination angle of $45^{\circ}$ is the most effective and shows the maximum equivalence heat transfer enhancement up to $300 \%$.

4) As a passive enhancement technique, nanofluids have superior heat transfer efficiency when employed with thicker twisted strips and helical baffles with a small helix angle which provides a maximum equivalence heat transfer rate of $255 \%$. In addition, twisted tape with nanofluids has a larger value of heat transfer of $89 \%$ as compared with the case of ordinary twisted tapes. On the other hand, wire coil inserts with grapheme oxidewater nanofluid improve the heat transfer rate up to $77 \%$.

5) The twisted tape inserts have the highest heat transfer enhancement of $400 \%$ followed by that for air-foil shaped inserts having a value of $300 \%$ followed by that for nanofluids with baffles having a value of $255 \%$ followed by that for wire coil having a value of $9 \%$.

\section{REFERENCES}

[1] Tabatabaeikia, S., Mohammed, H. A., Nik-Ghazali, N., and Shahizare1. B. (2014). Heat transfer enhancement by using different types of inserts. Hindawi Publishing Corporation Advances in Mechanical Engineering, (13) 250354.

[2] Shriwas, D., and Saini, J. (2018). Heat transfer enhancement technique in heat exchanger: An overview. IJRTI 3 (9), 2456-3315.

[3] Maradiya, C., Vadher, J., and Agarwal, R. (2018). The heat transfer enhancement techniques and their thermal performance factor. Journal of Basic and Applied Sciences, 7, 1-21.

[4] Lv, J.Y., Liu, Z.C., and Liu, W. (2020). Active design for the tube inserts of center-connected deflectors based on the principle of exergy destruction minimization. International Journal of Heat and Mass Transfer, 150(2020)119260.

[5] Kiran, K., Asalammaraja, Manoj, and Umesh, C. (2014). A review on effect of various types of tube inserts on performance parameters of heat exchanger. International Journal of Research in Advent Technology, 2 (6), 2321-9637.

[6] Klemes, J. J., Qiu-Wang, W., Varbanov, P., Zeng, M., China, H.H., Lal, N. S., Nian-Qi, Li., Wang, B., XueChao, W., and Walmsley, T.G. (2020). Heat transfer enhancement, intensification and optimization in heat exchanger network retrofit and operation. Renewable and Sustainable Energy Reviews, 120 (2020), 109644.

[7] Liu, S., and Sakra, M. (2013). A comprehensive review on passive heat transfer enhancements in pipe exchangers. Renewable and Sustainable Energy Reviews, 19, 64-81.

[8] Hasanpour, A., Farhadi, M., and Sedighi, K. (2014). A review study on twisted tape inserts on turbulent flow heat exchangers: The overall enhancement ratio criteria. International Communications in Heat and Mass Transfer, 02977, (10).

[9] Saha, S. K. (2020). Heat transfer fundamentals for design of heat transfer enhancement devices. Introduction to Enhanced Heat Transfer, Springer Briefs in Applied Sciences and Technology, doi: 10.1007/978-3-030-20740-3 11.

[10] Feng, S., Cheng, X., Qincheng, B., Pan, H., and Liu, Z. (2020). Experimental investigation on convective heat transfer of hydrocarbon fuel in circular tubes with twisted-tape inserts. International Journal of Heat and Mass Transfer, 146 (2020), 118817.

[11] Bhuiyan, M.M.K., Roshid, M., Talukder, M. M., Rasul, M. G., and Das, P. (2019). Influence of perforated triple twisted tape on thermal performance characteristics of a tube heat exchanger. doi: 10.1016/j.applthermaleng.2019.114769.

[12] Gugulothu, S.K. (2020). Computational fluid dynamics analysis in a ribbed tube with different twisted tape inserts to enhance the heat transfer. International Journal of Ambient Energy, doi: 10.1080/01430750.2020.1722224.

[13] Paneliya, S., Khanna, S., Mankad, V., Ray, Abhijit, Prajapati, P., and Mukhopadhyaya, I. (2019). Comparative study of heat transfer characteristics of a tube equipped with $\mathrm{X}$-shaped and twisted tape insert. 
[14] Samruaisin, P., Kunnarak, K., Chuwattanakul, V., and Eimear, S. (2019). Effect of sparsely placed twisted tapes installed with multiple-transverse twisted-baffles on heat transfer enhancement. Journal of Thermal Analysis and Calorimetry, doi:10.1007/s10973-019-09202-8.

[15] Wijayantaa, A. T., Yaningsiha, I., Juwana, W. E., Aziz, M., and Miyazaki, T. (2020). Effect of wing-pitch ratio of double-sided delta-wing tape insert on the improvement of convective heat transfer. International Journal of Thermal Sciences, 151 (2020), 106261.

[16] Liu, G., Yang, Chen, Zhang, Junhui., Zong, H., Xu, B., and Jin-yuan, Q. (2020). Internal flow analysis of a heat transfer enhanced tube with a segmented twisted tape insert. Institute of Process Equipment, College of Energy Engineering.

[17] Jundika. C., Kurniaa, Chaedir, B., Agus, P., and Sasmito (2020). Laminar convective heat transfer in helical tube with twisted tape insert. International Journal of Heat and Mass Transfer, 150 (2020) 119309.

[18] Sonawane, T., Patil1, Prafulla, Chavhan1, A., and Dusane, B. M. (2016). A review on heat transfer enhancement by passive methods. International Research Journal of Engineering and Technology, 3 (9).

[19] Abedin, M. Z and Sarkar, M. A. R. (2018). Experimental study of heat transfer enhancement through a tube with wire-coil inserts at low turbulent reynolds number. International Journal of Engineering Materials and Manufacture, 3(3) 122-133. doi: /10.26776/ijemm.03.03.2018.01.

[20] Goudarzi, K. and Jamali, H. (2017). Heat transfer enhancement of $\mathrm{Al}_{2} \mathrm{O}_{3}-\mathrm{EG}$ nanofluid in a car radiator with wire coil insert. Applied Thermal Engineering, 118, 510-517.

[21] Wanga, Y., Jorge, L., Alvarado, and Terrell, W. (2020). Thermal performance of helical coils with reversed loops and wire coil inserts. International Journal of Heat and Mass Transfer, 146, 118723.

[22] Virgilioa, M., Mayoa, I., Dedeynec, J., Geem, K.M. V., Marin, G.B., and Artsa, T. (2020). Effects of 2-D and 3-D helical inserts on the turbulent flow in pipes. Experimental Thermal and Fluid Science, 110, 109923.

[23] Gururatana, S. and Skullong, S. (2019). Experimental investigation of heat transfer in a tube heat exchanger with airfoil-shaped insert. Case Studies in Thermal Engineering, 14 (2019) 100462.

[24] Promvonge, P., Promthaisong, P. and Skullong, S. (2020). Experimental and numerical heat transfer study of turbulent tube flow through discrete $V$-winglets. International Journal of Heat and Mass Transfer, 151, 119351.

[25] Rashidi, S., Eskandarian, M., Mahian, O., and Poncet, S. (2018). Combination of nanofluid and inserts for heat transfer enhancement. Journal of Thermal Analysis and Calorimetry, doi:10.1007/s10973-018-70709.(0123456789. 